Research, part of a Special Feature on Scenarios of global ecosystem services

\title{
Changes in Nature's Balance Sheet: Model-based Estimates of Future Worldwide Ecosystem Services
}

\author{
$\underline{\text { Joseph Alcamo }}^{1}$, Detlef van Vuuren $^{2}$, Claudia Ringler $^{3}$, Wolfgang Cramer $^{4}$, Toshihiko Masui $^{5}$, \\ Jacqueline Alder $^{6}$, and Kerstin Schulze
}

\begin{abstract}
Four quantitative scenarios are presented that describe changes in worldwide ecosystem services up to 2050-2100. A set of soft-linked global models of human demography, economic development, climate, and biospheric processes are used to quantify these scenarios. The global demand for ecosystem services substantially increases up to 2050: cereal consumption by a factor of 1.5 to 1.7 , fish consumption (up to the 2020s) by a factor of 1.3 to 1.4 , water withdrawals by a factor of 1.3 to 2.0, and biofuel production by a factor of 5.1 to 11.3. The ranges for these estimates reflect differences between the socio-economic assumptions of the scenarios. In all simulations, Sub-Saharan Africa continues to lag behind other parts of the world. Although the demand side of these scenarios presents an overall optimistic view of the future, the supply side is less optimistic: the risk of higher soil erosion (especially in Sub-Saharan Africa) and lower water availability (especially in the Middle East) could slow down an increase in food production. Meanwhile, increasing wastewater discharges during the same period, especially in Latin America (factor of 2 to 4) and Sub-Saharan Africa (factor of 3.6 to 5.6) could interfere with the delivery of freshwater services. Marine fisheries (despite the growth of aquaculture) may not have the ecological capacity to provide for the increased global demand for fish. Our simulations also show an intensification of present tradeoffs between ecosystem services, e.g., expansion of agricultural land (between 2000 and 2050) may be one of the main causes of a 10\%-20\% loss of total current grassland and forest land and the ecosystem services associated with this land (e.g., genetic resources, wood production, habitat for terrestrial biota and fauna). The scenarios also show that certain hot-spot regions may experience especially rapid changes in ecosystem services: the central part of Africa, southern Asia, and the Middle East. In general, the scenarios show a positive balance of increasing services, especially in developing countries, and a negative balance of increasing risks and tradeoffs of services. The challenge, then, is dealing with these risks so as to avoid a future curtailment of ecosystem services.
\end{abstract}

Key Words: ecosystem services; environmental scenario analysis; global ecosystems; global environment; global natural resources; global scenarios; integrated assessment

\section{INTRODUCTION}

The concept of ecosystem services represents a new view on the relationship between society and nature. Ecosystem services are defined as the benefits people obtain from ecosystems (Millenium Ecosystem Assessment (MA) 2003). An overview of the current situation shows that nearly two-thirds of ecosystem services are found to be in decline worldwide (MA 2003) To better understand the status of these ecosystem services, the scientific community has undertaken a major effort under the auspices of the Millennium Ecosystem Assessment to assess both the current and future status of ecosystem services worldwide. A comprehensive MA scenario analysis has addressed the central question: "what will be the magnitude of changes in ecosystem services over the coming several decades?" (Carpenter et al. 2005). The scenario analysis produced two interlinked products, a set of qualitative scenarios and a set of quantitative

\footnotetext{
${ }^{1}$ Center for Environmental Systems Research, University of Kassel, Germany, ${ }^{2}$ Netherlands Environmental Assessment Agency, Bilthoven, Netherlands, ${ }^{3}$ International Food Policy Institute, Washington DC, USA, ${ }^{4}$ Potsdam Institute for Climate Impact Research, Germany, ${ }^{5}$ National Institute of Environmental Studies, Tsukuba, Japan, ${ }^{6}$ University of British Columbia, Vancouver, Canada, ${ }^{7}$ Center for Environmental Systems Research
} 
scenarios. This paper presents the main results of the quantitative scenarios, and the simulations used to derive them. We begin with an explanation of the global modeling analysis, followed by a description of the quantitative drivers of the scenarios. We then describe results of the scenarios, and discuss their uncertainty; finally, we provide an overview of some of the main conclusions derived from them.

\section{METHODOLOGY}

Scenarios are defined in the MA as "plausible descriptions of how the future may develop, based on a coherent and internally consistent set of assumptions about key relationships and driving forces." The formal procedure by which scenarios are developed, compared, and evaluated is called scenario analysis. A key objective of scenario analysis is to explore alternative future developments, and in the MA scenario analysis, four scenarios (Global Orchestration, Order from Strength, Adapting Mosaic, and TechnoGardensummarized in Table 1) were developed and compared. The four scenarios are distinguished by a tendency toward either stronger globalization or stronger regionalization, and by their emphasis on either economic growth or proactive management of ecosystems and their services (Table 1). In this paper, we describe how a set of models was used to evaluate future trends in ecosystem services implied by the quantitative scenarios.

The qualitative MA scenarios, or storylines, were generated through a set of dialogue workshops involving both experts and stakeholders, whereas the quantitative scenarios were computed by a set of global models. These two approaches are considered to be complementary. Qualitative scenarios allow greater flexibility in incorporating insights from different stakeholders and experts, and can be a platform for creative thinking. Quantitative scenarios can be used to test the assumptions of the qualitative scenarios, and provide geographic detail and numerical results that qualitative scenarios usually cannot provide.

The quantitative scenarios were developed as follows. First, a set of scenario drivers (defined below) were derived from the logic of the scenario storylines. Next, the drivers were input to a suite of state-of-the-art global simulation models covering different aspects of the global economicenvironment system (Table 2 and Fig. 1). These models were soft-linked, in that output files from one model were used as input files to another (Fig. $1) . \dagger$ The models were then used to compute temporal and spatial changes in ecosystem services. An overview of technical details of each of the models, as well as their main sources of uncertainty, is presented in Alcamo et al. (2005a). Readers can obtain more information by consulting the references cited later when particular model results are discussed.

We focus on results for 2050 as a compromise between the shorter time horizon of typical agricultural or urban prospective studies and the longer time horizon of climate impact studies. The year 2050 also provides a long-term perspective on the ecological consequences of current actions and policies. Where appropriate, we also provide information up to the year 2100 .

\section{DRIVERS OF FUTURE ECOSYSTEM SERVICES}

The capacity of ecosystems to provide services is determined by many human-induced factors that cause changes in an ecosystem. Direct drivers have a direct influence on ecosystem services, whereas indirect drivers operate indirectly, often by altering one of the more direct drivers (MA 2003).

\section{Indirect Drivers}

The main indirect drivers taken into account in our analysis are:

- Population development. In the MA scenarios, global population in 2050 ranges from approximately 8.1 billion under Global Orchestration to 9.6 billion under Order from Strength, with slow or even negative growth rates within industrialized regions, and higher growth rates in developing countries (Table 3).

- Economic development. The MA scenario with the slowest overall economic growth rates (Order from Strength) nevertheless experiences a doubling of global average per capita GDP between 1995 and 2050. Under the fastest growing scenario (Global Orchestration), per capita income increases 
Table 1. Overview of the four Millennium Ecosystem Assessment scenarios

\begin{tabular}{ll}
\hline \hline Scenario & Description \\
\hline Global Orchestration & $\begin{array}{l}\text { Globally connected society that focuses on global trade and } \\
\text { economic liberalization. Takes a reactive approach to } \\
\text { ecosystem problems, but also takes strong steps to reduce } \\
\text { poverty and inequality and to invest in public goods, such as } \\
\text { infrastructure and education. }\end{array}$ \\
Order from Strength & $\begin{array}{l}\text { Regionalized and fragmented world, concerned with security } \\
\text { and protection. A world that emphasizes regional markets, } \\
\text { paying little attention to public goods, and takes a reactive } \\
\text { approach to ecosystem problems. }\end{array}$ \\
Adapting Mosaic & $\begin{array}{l}\text { Regional watershed-scale ecosystems are the focus of } \\
\text { political and economic activity. Local institutions are } \\
\text { strengthened and local ecosystem management strategies are } \\
\text { common; societies develop a strongly proactive approach to } \\
\text { the management of ecosystems. }\end{array}$ \\
TechnoGarden & $\begin{array}{l}\text { Globally connected world relying strongly on } \\
\text { environmentally sound technology. This world uses highly } \\
\text { managed, often engineered, ecosystems to deliver ecosystem } \\
\text { services, and takes a proactive approach to the management } \\
\text { of ecosystems in an effort to avoid problems. }\end{array}$
\end{tabular}

by a factor of four. Although the economic growth of industrialized countries slows down, the growth of developing regions is higher than between 1971-2000 (Table 4).

- Technology development. This refers to the impact of technological development on the efficiency of resource use. Technology development is represented, for example, by increasing the assumed efficiency of domestic water use and crop yields over time.

- Human behavior is included indirectly in the modeling analysis by changing model coefficients reflecting the willingness of people to invest time or money in energy conservation or water conservation.

- Institutional factors refer to the impacts of institutions on education, international trade, and international technology transfer. Institutional factors are represented in different ways in the modeling analysis, for example in the form of an elasticity function between income level of a country and the average years of education of its citizens.
- Energy and agricultural demand and production have an ambiguous status in the MA scenarios. They are indirect drivers because they influence direct drivers such as greenhouse gas emissions and land-use change. But productions of biofuels and food are also considered ecosystem services, as explained later in this paper.

In the modeling analysis, we specify the future trends of indirect drivers in a way consistent with the storylines of the scenarios. For example, statements about high or low mortality in the storylines were interpreted to mean that the trend in mortality is in the upper or lower $20 \%$ of probabilistic demographic projections. The assumptions for indirect drivers are described in Alcamo et al. (2005a) and Nelson et al. (2005).

\section{Direct Drivers}

The direct drivers taken into account in the MA scenario analysis include greenhouse gas emissions, air pollution emissions, risk of acidification and 
Table 2. Models used in MA global modeling exercise

\begin{tabular}{ll}
\hline \hline Model & Description \\
\hline IMPACT & $\begin{array}{l}\text { Model developed by the International Food Policy Research } \\
\text { Institute in the United States; computes global food supply, } \\
\text { demand, trade, and international food prices for countries and } \\
\text { regions (Rosegrant et al. 2002). }\end{array}$
\end{tabular}

WaterGAP

AIM

IMAGE 2.2

Ecopath with Ecosim

Aquatic Freshwater Biodiversity model

Terrestrial Biodiversity model
Model developed at the University of Kassel in Germany; computes global water use, availability, stress, and return flows on a river basin scale (Alcamo et al. 2003a, 2003b).

A global change integrated model developed by the National Institute for Environment Studies in Japan; computes land cover and other indicators of global change worldwide, with an emphasis on Asia (Kainuma et al. 2002).

A global change model developed by the National Institute of Public Health and the Environment in the Netherlands; computes climate and global land cover on a grid scale and several other indicators of global change (Alcamo et al. 1998, IMAGE-team 2001).

Model developed by the University of British Columbia in Canada; computes dynamic changes in selected marine ecosystems as a function of fishing efforts (Pauly et al. 2000).

Developed as part of the Millenium Ecosystem Assessment; identifies changes in the number of fish species on a river basin scale as a function of changing river runoff (Sala et al. 2005, Xeonoupoulus et al. 2005).

Developed as part of the Millennium Ecosystem Assessment; computes aggregated changes in terrestrial biodiversity as a function of loss of habitat, climate change, nitrogen deposition, and introduction of alien species (Sala et al. 2005). excess nitrogen emissions, climate change, sea level rise, changes in land use and land cover, the use of nitrogen fertilizers, and nitrogen loading to rivers and coastal marine systems. A detailed description of the quantitative estimates for direct drivers in the MA scenarios are given in Alcamo et al. (2005a) and Nelson et al. (2005). Changes in land use under the MA scenarios are described later in this paper. In the following paragraphs, we describe the trends of two important direct drivers, climate change and nitrogen loading to coastal marine ecosystems.

\section{Climate change}

The IMAGE 2.2 integrated assessment model is used to compute the trend of greenhouse gas emissions as a function of energy and agricultural production in the MA scenarios (Alcamo et al. 1998, IMAGE Team 2001). The IMAGE model is also used to compute climate change resulting from greenhouse gas emissions. A large increase in emissions is computed for all scenarios except under TechnoGarden. The strongest increases (a factor of about 2.5 relative to year 2000) occur in Global Orchestration (driven especially by major increases in economic activity) and in Order from Strength (driven by population growth and use of domestic energy resources, such as coal in many Asian countries). Emissions peak around 2060 under Global Orchestration, but continue to increase beyond 2100 under Order from Strength. Compared with the other MA scenarios, emissions under 
Fig. 1. Models used for global modeling exercise, and the main flow of information between them. Modeling of freshwater and terrestrial biodiversity is not covered in this paper.

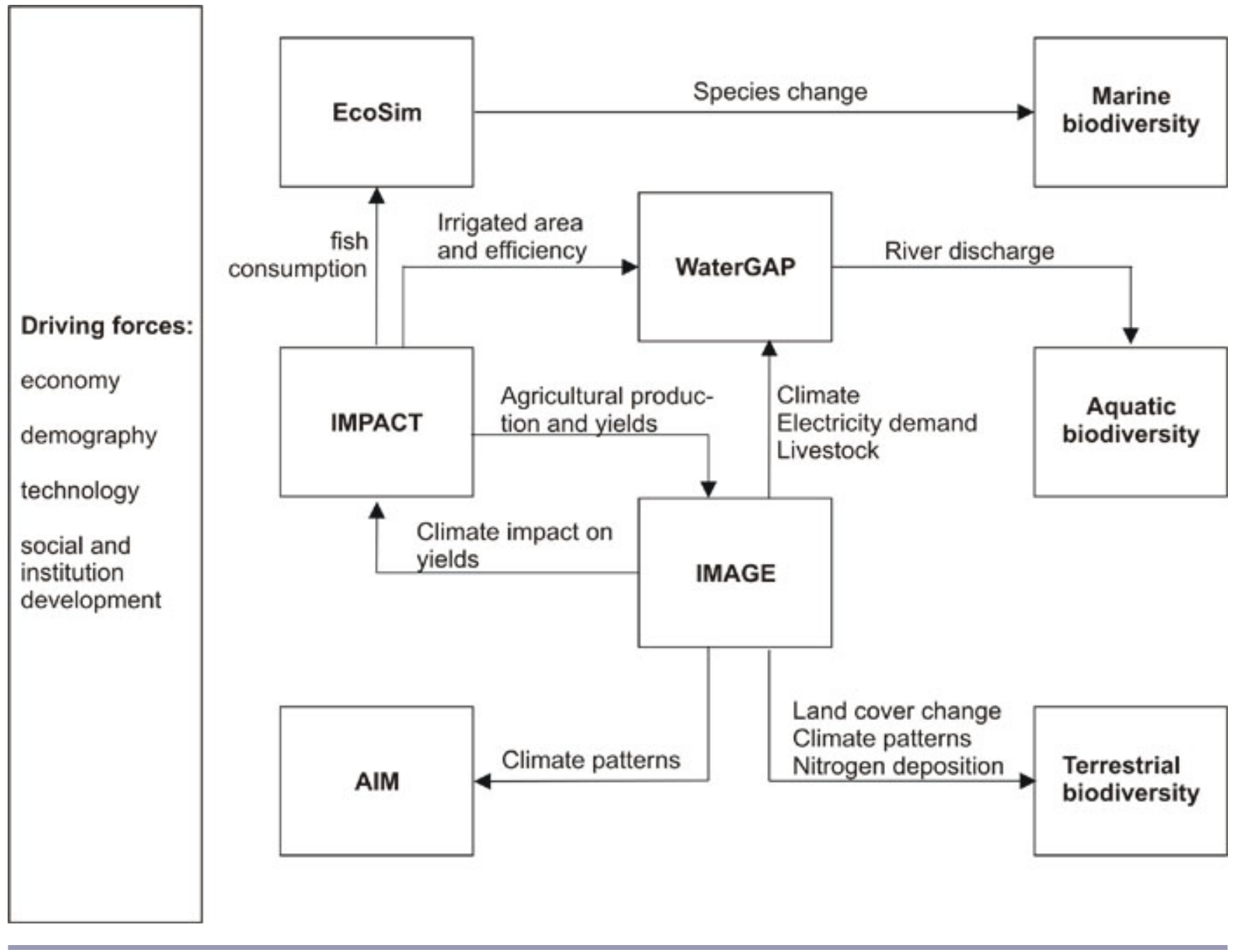

TechnoGarden sink below current levels by 2100 as a result of strong international climate policies.

Because of the long-term accumulation of greenhouse gases in the atmosphere, global mean temperature is computed to increase under all MA scenarios, ranging from $1.6^{\circ} \mathrm{C}$ (TechnoGarden) to $2.0^{\circ} \mathrm{C}$ (Global Orchestration) above pre-industrial temperature levels. The relatively small difference between scenarios is explained by the long lag time between the build-up of emissions in the atmosphere and the response of the climate system to this buildup. Results from climate models suggest that regional changes in temperature are likely to differ from global averages. For example, models typically compute larger temperature increases in arctic and temperate zones compared with the tropics.

The impacts of climate change are uncertain given the lack of knowledge about the spatial pattern of change and response of different ecosystems. However, it seems likely that ecosystems with low adaptive capacity, such as coral reefs and alpine ecosystems (Intergovernmental Panel on Climate Change (IPCC) 2001), will be particularly 
Table 3. Overview of assumptions about populations by region in the MA scenarios (millions of people) Source: IIASA

\begin{tabular}{|c|c|c|c|c|c|c|c|c|c|c|c|c|c|}
\hline \multirow[t]{2}{*}{ Region } & \multirow{2}{*}{$\frac{\text { Current }}{1995}$} & \multicolumn{3}{|c|}{ Global Orchestration } & \multicolumn{3}{|c|}{ Order from Strength } & \multicolumn{3}{|c|}{ Adapting Mosaic } & \multicolumn{3}{|c|}{ TechnoGarden } \\
\hline & & 2020 & 2050 & 2100 & 2020 & 2050 & 2100 & 2020 & 2050 & 2100 & 2020 & 2050 & 2100 \\
\hline $\begin{array}{l}\text { Former Soviet } \\
\text { Union }\end{array}$ & 285 & 290 & 282 & 245 & 287 & 257 & 216 & 288 & 273 & 246 & 292 & 281 & 252 \\
\hline Latin America & 477 & 637 & 742 & 681 & 710 & 944 & 1309 & 708 & 933 & 1155 & 672 & 831 & 950 \\
\hline $\begin{array}{l}\text { Middle East and } \\
\text { North Africa }\end{array}$ & 312 & 478 & 603 & 597 & 539 & 774 & 972 & 537 & 765 & 924 & 509 & 692 & 788 \\
\hline OECD & 1020 & 1136 & 1255 & 1153 & 1076 & 998 & 856 & 1079 & 1068 & 978 & 1117 & 1154 & 1077 \\
\hline Asia & 3049 & 3861 & 4104 & 3006 & 4210 & 5023 & 5173 & 4201 & 4992 & 4753 & 4039 & 4535 & 3992 \\
\hline Sub-Saharan Africa & 558 & 858 & 1109 & 1132 & 956 & 1570 & 1988 & 951 & 1492 & 1775 & 907 & 1329 & 1516 \\
\hline World & 5701 & 7260 & 8095 & 6814 & 7777 & 9567 & 10514 & 7764 & 9522 & 9830 & 7537 & 8821 & 8575 \\
\hline
\end{tabular}

vulnerable to the climate change occurring under the MA scenarios.

\section{Nitrogen loading to coastal marine systems}

Human activities, in particular agriculture and industry, have greatly modified the flux of nitrogen at the global scale (e.g., Green et al. 2004). This includes not only increasing levels of nitrogen deposition from the atmosphere, but also an increased loading of nitrogen from rivers causing the eutrophication of coastal marine systems. The change of loading at a global scale has been estimated for the MA scenarios by using the model of van Drecht et al. (2003), and by estimating changes in nitrogen deposition, use of nitrogen fertilizers and manure in agriculture, and release of nitrogen from sewage systems. With the exception of the TechnoGarden scenario, the MA scenarios show an increase in global river loading to coastal ecosystems ranging from approximately $10 \%$ to $30 \%$ (depending on the scenario) between 1995 and 2030. The TechoGarden scenario shows a $10 \%$ decrease because a high level of nitrogen removal from sewage was assumed and a lower level of nitrogen oxide emissions and nitrogen deposition were computed for this scenario.

\section{PROVISIONING ECOSYSTEM SERVICES}

The MA has classified ecosystem services into four categories: provisioning, regulating, supporting, and cultural services (MA 2003). In this paper, we focus on the services and indicators amenable to modeling analysis. We begin with estimates of provisioning ecosystem services, which are services that produce goods directly consumed by humans. According to MA (2003) these include:

- Food (all food products derived from plants, animals, and microbes);

- $\quad$ Fuels (fuelwood and modern biofuel crops);

- Freshwater (as water supply for households, industry, agriculture, and other water-using sectors, and as habitat for the freshwater fishery);

- Fiber (materials such as wood, jute, hemp, silk, and several other products);

- Genetic resources (genetic information used for animal and plant breeding and biotechnology); 


\section{Former Latin Ame- $\quad$ Middle East OECD Asia $\quad$ Sub-Saharan World Soviet Union rica and North Africa America}

Historic

$\begin{array}{llllllll}1971-2000 & 0.4 & 1.2 & 0.7 & 2.1 & 5.0 & -0.4 & 1.4\end{array}$

Global Orchestration

$\begin{array}{llllllll}1995-2020 & 3.5 & 2.8 & 2.0 & 2.5 & 5.1 & 1.7 & 2.4 \\ 2020-2050 & 4.9 & 4.3 & 3.4 & 1.9 & 5.3 & 4.0 & 3.0 \\ 2050-2100 & 3.1 & 2.2 & 2.5 & 1.3 & 3.1 & 4.1 & 2.3\end{array}$

Order from Strength

$\begin{array}{cccccccc}1995-2020 & 2.2 & 1.8 & 1.5 & 2.1 & 3.2 & 1.0 & 1.4 \\ 2020-2050 & 2.6 & 2.3 & 1.8 & 1.3 & 2.4 & 2.1 & 1.0 \\ 2050-2100 & 2.7 & 1.8 & 1.9 & 0.9 & 2.1 & 2.1 & 1.3\end{array}$

Adapting Mosaic

$\begin{array}{llllllll}1995-2020 & 2.6 & 2.0 & 1.6 & 2.0 & 3.8 & 1.2 & 1.5 \\ 2020-2050 & 4.0 & 3.0 & 2.4 & 1.6 & 4.1 & 2.9 & 1.9 \\ 2050-2100 & 3.1 & 2.2 & 2.4 & 1.2 & 2.5 & 3.3 & 1.9\end{array}$

TechnoGarden

$\begin{array}{llllllll}1995-2020 & 2.9 & 2.4 & 1.7 & 2.2 & 4.2 & 1.4 & 1.9 \\ 2020-2050 & 4.5 & 3.9 & 3.3 & 1.7 & 4.7 & 3.8 & 2.5 \\ 2050-2100 & 3.1 & 2.2 & 2.5 & 1.4 & 3.1 & 4.1 & 2.3\end{array}$

- Biochemicals, natural medicines, pharmaceuticals, and ornamental resources.

In the following paragraphs, we present results for the three provisioning services that can at least partly be quantified with existing global models: food, freshwater, and fuel.

\section{Food Consumption and Production}

\section{Scenarios of food demand and production}

Food is obviously one of the most important services provided to society by terrestrial and aquatic ecosystems. To describe these services, we use indicators that are related to both demand and supply of food. The IMPACT model, used for agricultural calculations (Rosegrant et al. 2001), mimics the complex relationships in the world's agriculture system. The main drivers of the model are global and regional demands for food. The higher the future investments in agriculture, the faster the technological developments in this sector and the greater the inputs such as fertilizer or irrigation, and hence the higher the crop yields. The higher the national income per person, the greater the per capita purchasing power, and hence the higher the food demand, up to some saturation level (depending on a system of supply and demand elasticities). Higher 
domestic prices stimulate more food production as well as international food trade, and open trade policies lead to cheaper imports and more costeffectively grown crops, and eventually lower food prices. These assumed modeling relationships are combined with scenario assumptions about future population and income growth, dietary preferences, trade policies, and other variables to compute a unique pathway for food consumption and production for each country or group of countries in the world.

A key indicator of services provided by agriculture is the consumption of food per person. This is a good indicator for regions suffering from chronic malnutrition, such as Sub-Saharan Africa, but less relevant for the Organization of Economic Cooperation and Development (OECD) and other richer regions, where average consumption is already high and where diet quality and obesity are more important issues. All scenarios show small increases in the grain consumed per person, going up fastest in the Global Orchestration scenario because of higher income growth and greater average per capita purchasing power. Global trends, however, mask large regional differences (Fig. 2). Large increases in consumption in Asia indicate increasing well-being, whereas smaller increases in Sub-Saharan Africa indicate continuing gaps in food availability. In other regions, food consumption reaches saturation levels.

The demand for meat reflects both increased purchasing power and changing food preferences (Fig. 3). An increase in meat consumption also has a magnifying effect on cereal consumption because new livestock require additional feed. Meat consumption is highest under Global Orchestration because of higher income and fast production growth, with great variations between regions, depending on cultural preferences for meat vs. nonmeat products. A lower preference for meat in developed countries for health reasons leads to a lower increase in meat consumption in TechnoGarden. Under all scenarios, meat consumption remains low in Sub-Saharan Africa.

The total production of food and feed in different regions is another indicator of the services provided by agricultural systems. The rapid increase in meat consumption in most of the developing world drives increased cereal demand as livestock feed. All scenarios show large regional changes in cereal production (Fig. 4), which has important implications for the future intensity and expansion of agricultural land. Asia shows the largest changes in production because of large changes in both income and population, whereas the large increases in Sub-Saharan Africa stem primarily from population rather than economic growth.

\section{Scenarios of land-use changes}

Food production requires land, and thus has an important impact on the provision of other ecosystem services. Expansion of agricultural land at the expense of natural grassland or forest is likely to eliminate many of the ecosystem services provided on this land. Conversely, the abandonment of agricultural land in high-income regions opens up the possibility of providing new services on this land if grassland or forest are re-established. The amount of agricultural land needed in different regions in the future depends on the computed food production, food trade, food prices, technology, suitability of land, and competition for land. These factors are taken into account by a combination of the IMPACT (Rosegrant et al. 2001) and IMAGE 2.2 models (Alcamo et al. 1998, IMAGE Team, 2001). These models are used to compute the amount of cropland and pastureland needed to satisfy the production of food (Fig. 5).

Agricultural land decreases in area in OECD and former Soviet Union (FSU) countries under most scenarios because of stabilizing population, saturating per capita food demands, and increasing crop yields due to technological developments (Fig. 5). The largest expansion of agricultural land occurs in developing countries under the Order from Strength scenario because of high population growth and low agricultural investments, leading to slower improvements in crop yield. Moreover, barriers to world food trade in this scenario imply inefficiencies in crop production. Under this scenario agricultural land in Sub-Saharan Africa increases from approximately 11 to 17 Mha between 2000 and 2050, which causes a major shift in ecosystem services from natural grassland and forest to agricultural land.

The second highest expansion of agricultural land in developing countries occurs under the Global Orchestration scenario because of increases in food production driven by economic growth (despite higher crop yields and more intense world food trade). The lowest expansion of agricultural land occurs under the Adapting Mosaic scenario, where 
Fig. 2. Cereal consumption in 2050 by region under four scenarios (kg per capita per year). FSU = Former Soviet Union, SSA = Sub-Saharan Africa, LAM = Latin America, MENA = Middle East \& North Africa. Scenario names: $\mathrm{GO}=$ Global Orchestration; $\mathrm{TG}=$ TechnoGarden; $\mathrm{AM}=$ Adapting Mosaic; OS=Order from Strength. IMPACT model calculations.
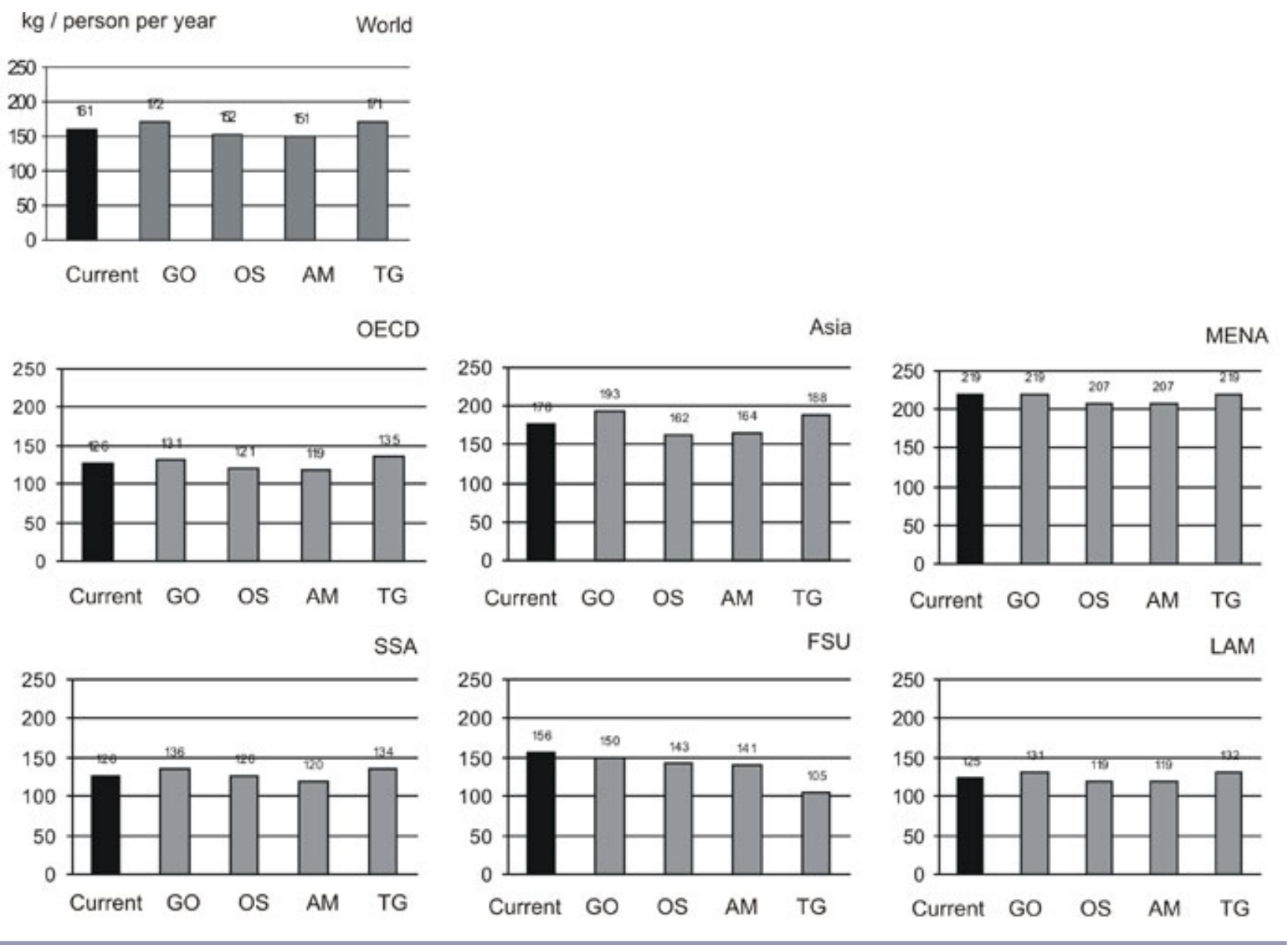

food production is relatively low, and the TechnoGarden scenario, where increasing crop yield keeps up with increased food production (Fig. 5 ). These trends are also reflected in changes of forest cover. Order from Strength has the highest deforestation rate, and Adapting Mosaic and TechnoGarden the lowest. The four scenarios indicate that a total of $10 \%$ to $20 \%$ of current grassland and forest area (warm mixed forests, tropical woodlands, and tropical forests) may be lost by 2050 , mostly because of the expansion of agricultural land. The global trends are a net result of slow reforestation in the temperate zones, and strong deforestation in the tropical zones. The biodiversity impacts of these land-use changes have been estimated by Sala et al. (2005).

\section{Major uncertainties}

The scenarios as a whole show significant increases in global food production. But the global picture masks significant regional variations. A lag in purchasing power implies that food deficiencies and child malnutrition may continue to trouble much of Sub-Saharan Africa. Later, we also point out the risks to world agriculture posed by increasing soil erosion, water stress, and other ecological sideeffects. The MA's Conditions and Trends Report 
Fig. 3. Meat consumption in 2050 [kg per person per year]. FSU = former Soviet Union, SSA = SubSaharan Africa, LAM = Latin America, MENA = Middle East \& North Africa. Scenario names: GO= Global Orchestration; TG = TechnoGarden; AM=Adapting Mosaic; OS=Order from Strength. IMPACT model calculations.
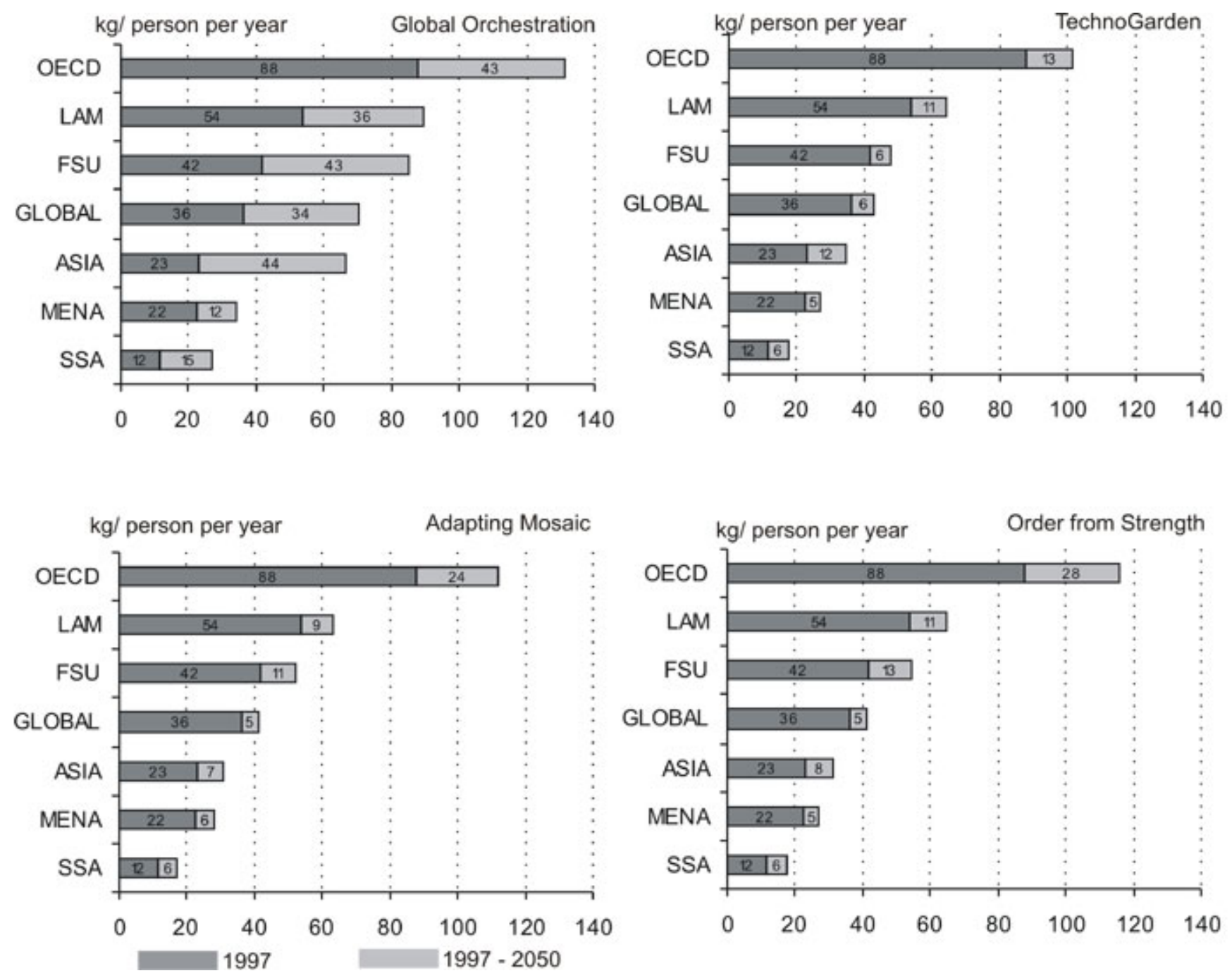

(MA, 2005) points out an additional uncertainty in the estimates of land-cover change, namely, the lack of consistent, replicable data on the extent of forests and other land-cover types that can be tracked over time.

\section{Fish Consumption and Production}

\section{Scenarios for fish consumption and production}

Because fish are an important protein source for much of the world, fish supply is an important service provided by aquatic ecosystems. Future global consumption of fish under the MA scenarios is estimated with the IMPACT model, and fish production is computed using the EcoSim/EcoPath 
Fig. 4. Cereal production in 2050 by region under four scenarios (megatons per year). FSU = former Soviet Union, $\mathrm{SSA}=$ Sub-Saharan Africa, LAM = Latin America, MENA = Middle East \& North Africa. Scenario names: $\mathrm{GO}=$ Global Orchestration; TG = TechnoGarden; AM=Adapting Mosaic; OS=Order from Strength. IMPACT model calculations.
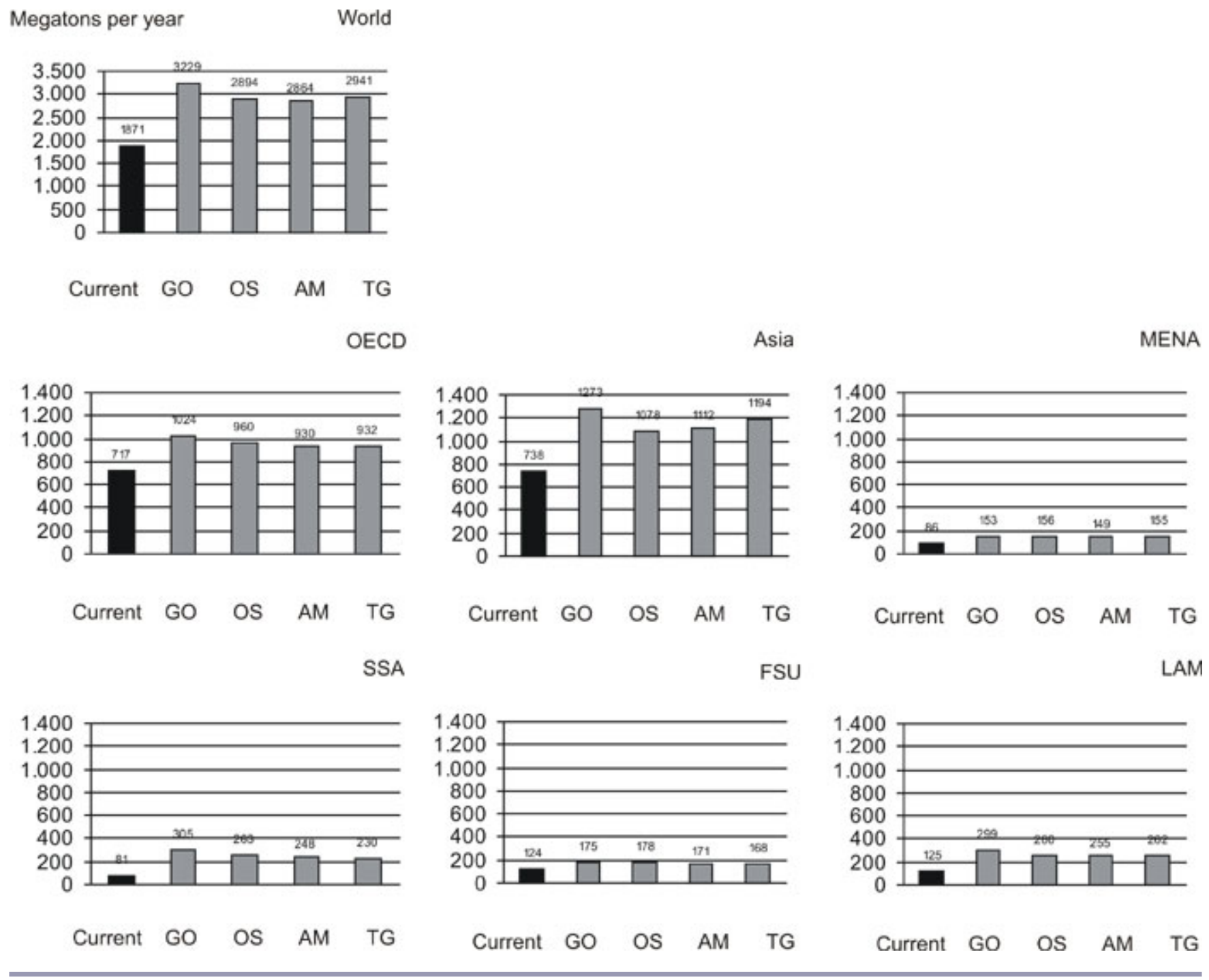

model (Pauly et al. 2003) for three important regional marine fisheries. +

Under the Global Orchestration scenario, global average consumption of fish increases between the late 1990s and 2020 from around 15.7 to $17.3 \mathrm{~kg}$ per capita per annum. (Here, we use a shorter time horizon because of the unavailability of calculations for 2050.) Multiplying per capita consumption by global population indicates that total fish consumption grows from around 90 to $128 \mathrm{Mt} \mathrm{a}^{-1}$ over the same period. Fish consumption also increases under the other scenarios. It is not clear, however, whether this increasing demand can be met by world fisheries, because many important fishing areas are already fully exploited or overharvested (Pauly et al. 2003). In recent decades, growing fish consumption especially in Asia has been fulfilled by the rapid expansion of aquaculture (a global increase from 2 to $25 \mathrm{Mt} \mathrm{a}^{-1}$ between 1973 
Fig. 5. Area of different land uses in 2050 by region $\left(\right.$ millions $\left.\mathrm{km}^{2}\right)$. FSU $=$ Former Soviet Union, $\mathrm{SSA}=$ Sub-Saharan Africa, LAM = Latin America, MENA = Middle East \& North Africa. Scenario names: GO= Global Orchestration; TG = TechnoGarden; AM=Adapting Mosaic; OS=Order from Strength. IMAGE 2.2 model calculations.
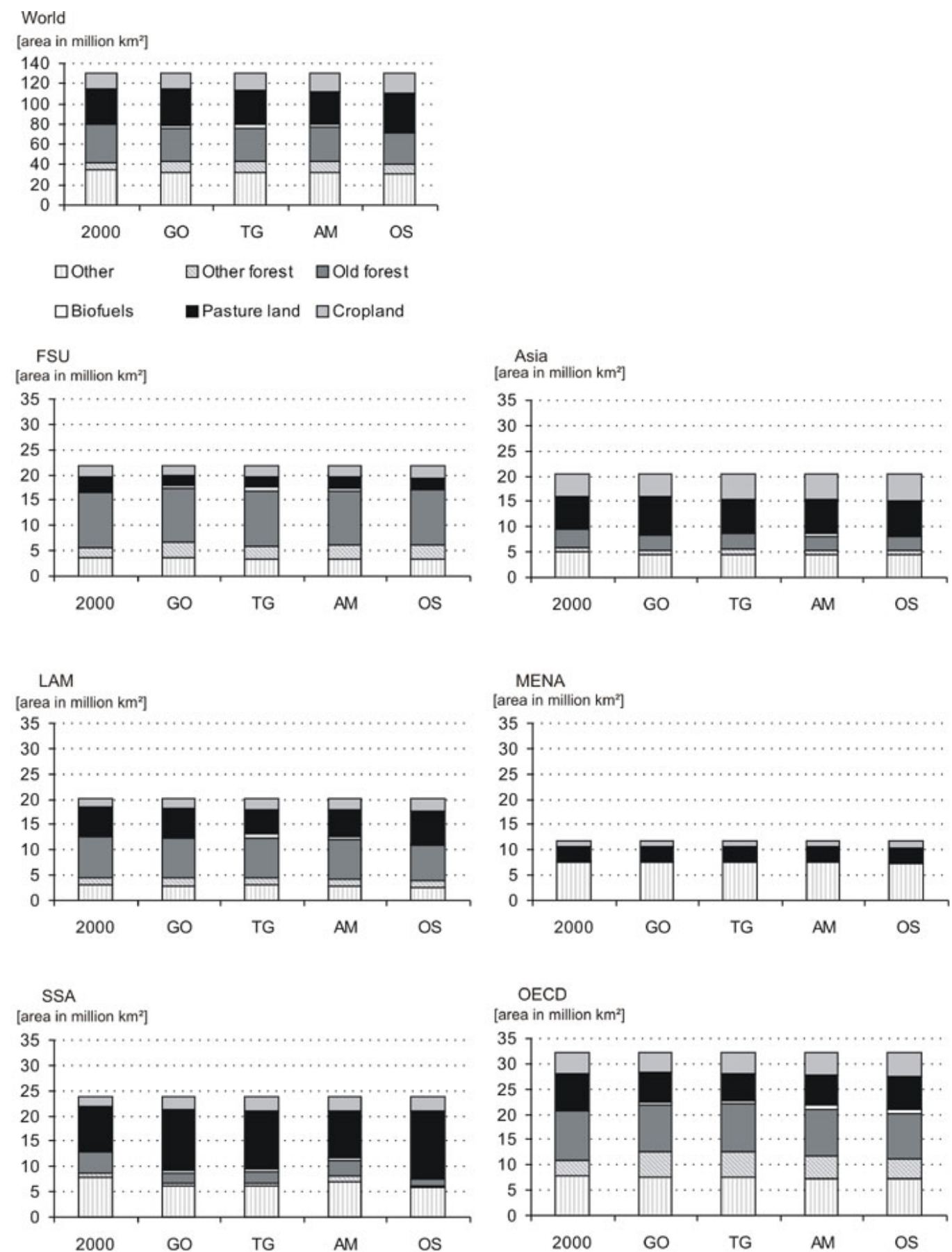
Fig. 6. Fish landings in four scenarios up to 2050 in three marine fisheries (tonnes per year). Scenario names: $\mathrm{GO}=$ Global Orchestration; TG=TechnoGarden; $\mathrm{AM}=$ Adapting Mosaic; OS=Order from Strength. Ecopath/Ecosim model calculations.

\section{Gulf of Thailand}
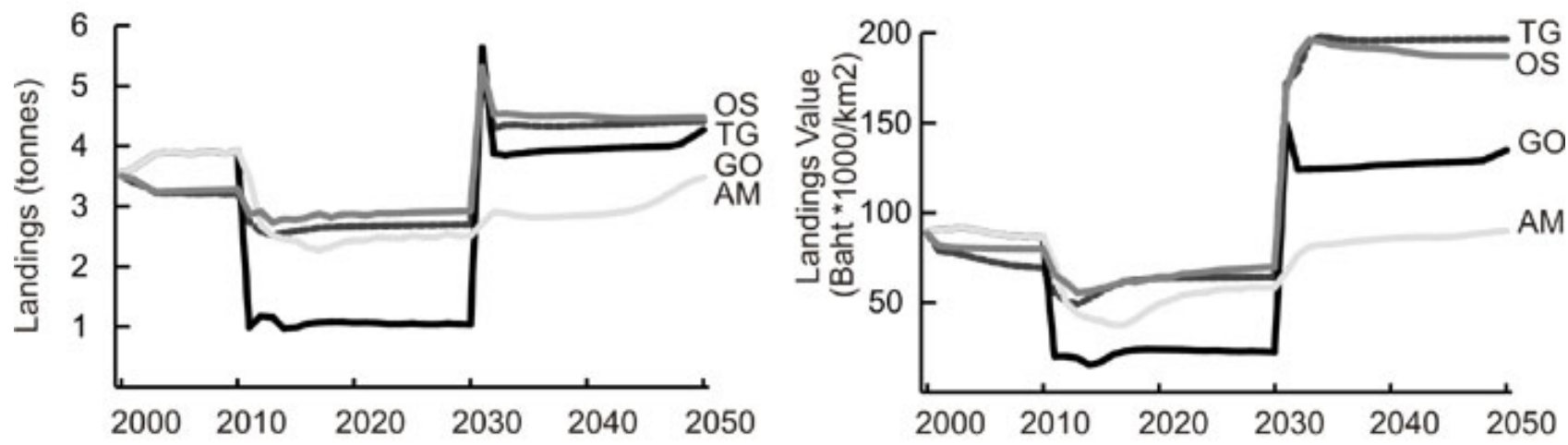

Central North Pacific
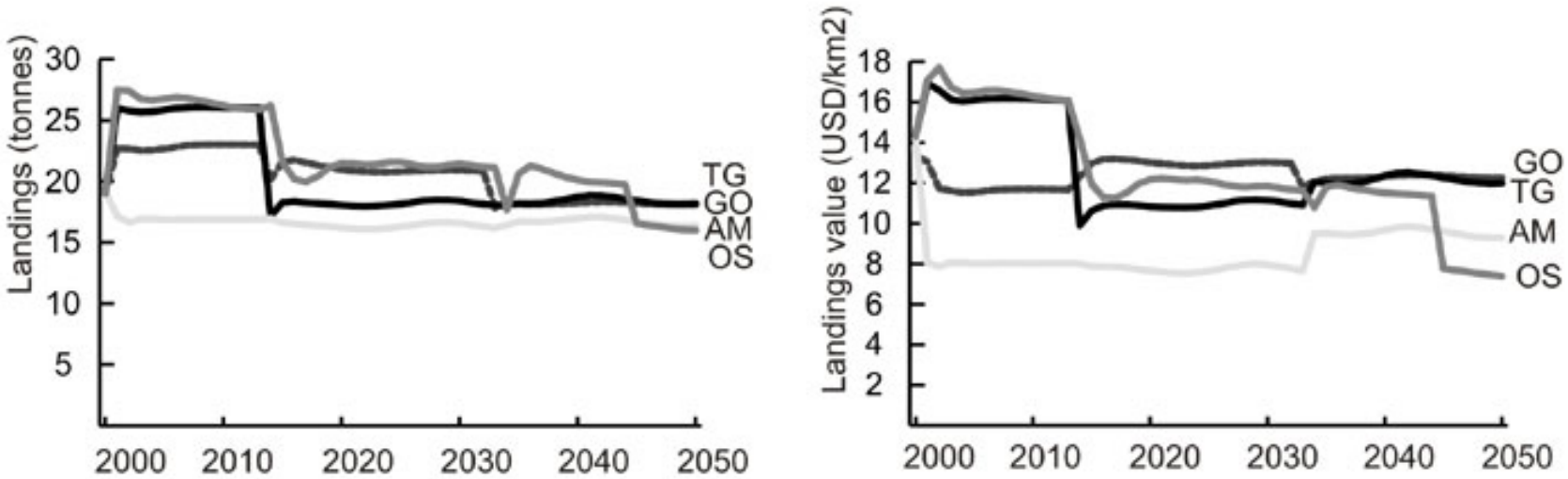

North Benguela
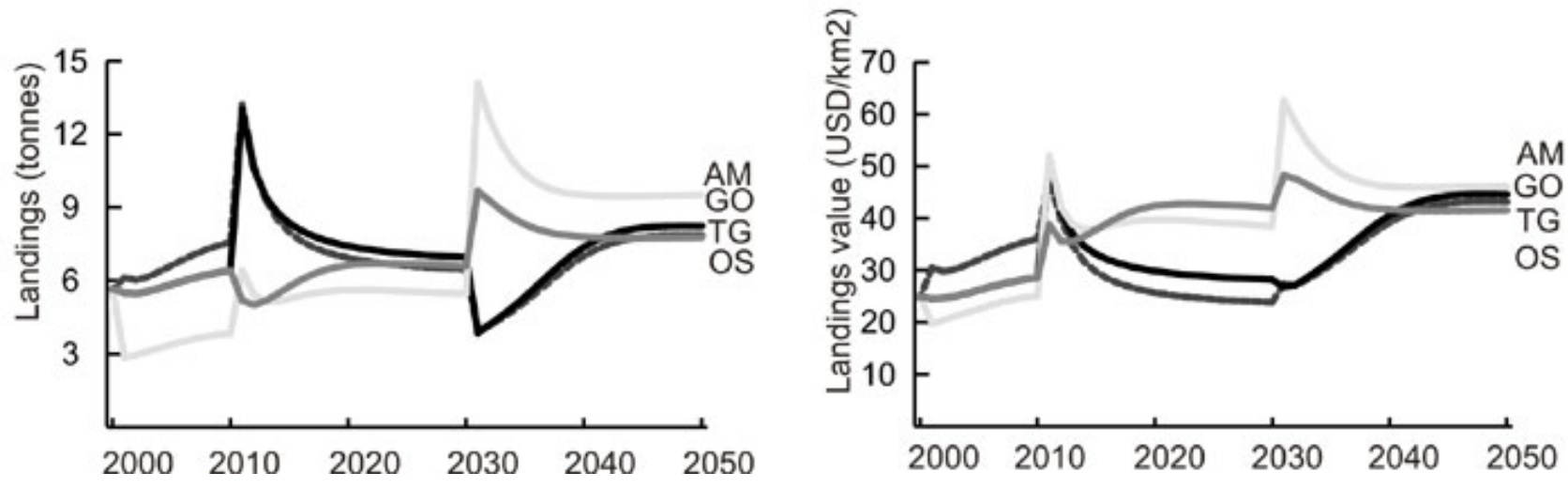
and 1997; Pauly et al. 2003) This has had an important effect on marine fisheries because a large fraction of feed for aquaculture comes from fish meal and fish oil derived from marine species. Hence, the future source of feed for aquaculture is an important uncertainty. For its fish production estimates, the EcoSim/EcoPath model takes into account not only the future source of feed for aquaculture, but also future subsidies for the fishing industry, the management objectives of fishing (either to optimize employment or profits), and the impact of climate change on shifts in species distribution and abundance (Pauly et al. 2003). For all scenarios, fish catch (by weight) is maintained in the North Benguela fishery, not maintained in the Central North Pacific, and has mixed results in the Gulf of Thailand (Fig. 6). The overall message of these results is that it is uncertain whether future demands for fish can be sustainably provided by either aquaculture or marine fisheries.

\section{Major uncertainties}

A major uncertainty of the foregoing calculations is the lack of a consistent global modeling approach that combines both detailed demand and supply calculations, and that also factors in possible global ecological constraints to fish production. Our analysis indicates that another major uncertainty is the question of whether global aquaculture can partly substitute for capture fishing-without creating new pressures on ecosystems.

\section{Services from Freshwater Systems}

\section{Scenarios of freshwater availability and use}

Freshwater ecosystems provide society with the essential services of water supply for its sustenance, economic activity, and recreation, as well as habitat for its freshwater fishery. The WaterGAP model, used to quantify freshwater-related ecosystem services, computes water availability on a grid and river basin scale by taking into account precipitation/snowmelt, evaporation, groundwater storage and runoff. The model estimates future water withdrawals according to changes in income, population, and electricity demand (Alcamo et al. 2003a, 2003b).

As one indicator of freshwater services, we use water availability - the total volume of water in a river basin that is annually renewed by precipitation and theoretically available to support society's water uses, as well as habitat for freshwater ecosystems. In reality, society can exploit only a small fraction of this volume because of geographic and temporal constraints or lack of storage facilities.

Water availability increases up to 2100 over most river basins and all scenarios because of a net increase in precipitation related to climate change (Fig. 7). (We use 2100 here rather than a time horizon of 2050 to illustrate the longer-term impacts of climate change, which are likely to intensify over the course of the century.) Differences between scenarios are not large because the climate system responds to cumulative emissions, which are not very different between the scenarios. Although most regions have a net increase in water availability, our analysis indicates a decrease of runoff in the already arid and water-short Middle East and Northern Africa (MENA). It should be noted that, although a net increase in precipitation tends to increase overall water availability, it may also lead to an increase in extremely high runoff events (see, e.g., Lehner et al. 2005).

As water availability indicates the volume of water theoretically exploitable, water withdrawals indicate the volume used by society to fulfill its domestic, industrial, and agricultural needs. (Scenario results for the freshwater fishery are shown elsewhere; Xenopoulous et al. 2005.) Compared with availability, water withdrawals show large changes over time between current conditions and 2050 (Fig. 7). Strong economic growth coupled with an increase in population leads to a worldwide increase in withdrawals of around $40 \%$ under the Global Orchestration scenario. But the changes are only slight in the OECD, MENA, and FSU because of compensating effects: improving water efficiency tends to lower water use whereas economic and population growth tends to increase it. Under the TechnoGarden scenario, strong structural changes in the domestic and industrial sectors and improvements in the efficiency of water use in all sectors lead to decreases in water withdrawals in OECD and FSU countries and slower increases elsewhere compared with other scenarios. Although the Adapting Mosaic and Order from Strength scenarios do not have the largest economic growth, they have the largest withdrawals because of slower improvement in the efficiency of water use and faster population growth. Increases in developing countries from 1995 to 2050 are very large, especially in Latin 
Fig. 7. (a) Water availability in 2100 [1000 $\mathrm{km}^{3}$ per year]. (b) Water withdrawals in 2050 [1000 $\mathrm{km}^{3}$ per year]. FSU = Former Soviet Union, SSA = Sub-Saharan Africa, LAM = Latin America, MENA = Middle East \& North Africa. Scenario names: GO=Global Orchestration; TG = TechnoGarden; AM=Adapting Mosaic; OS=Order from Strength. WaterGAP model calculations.

(a)
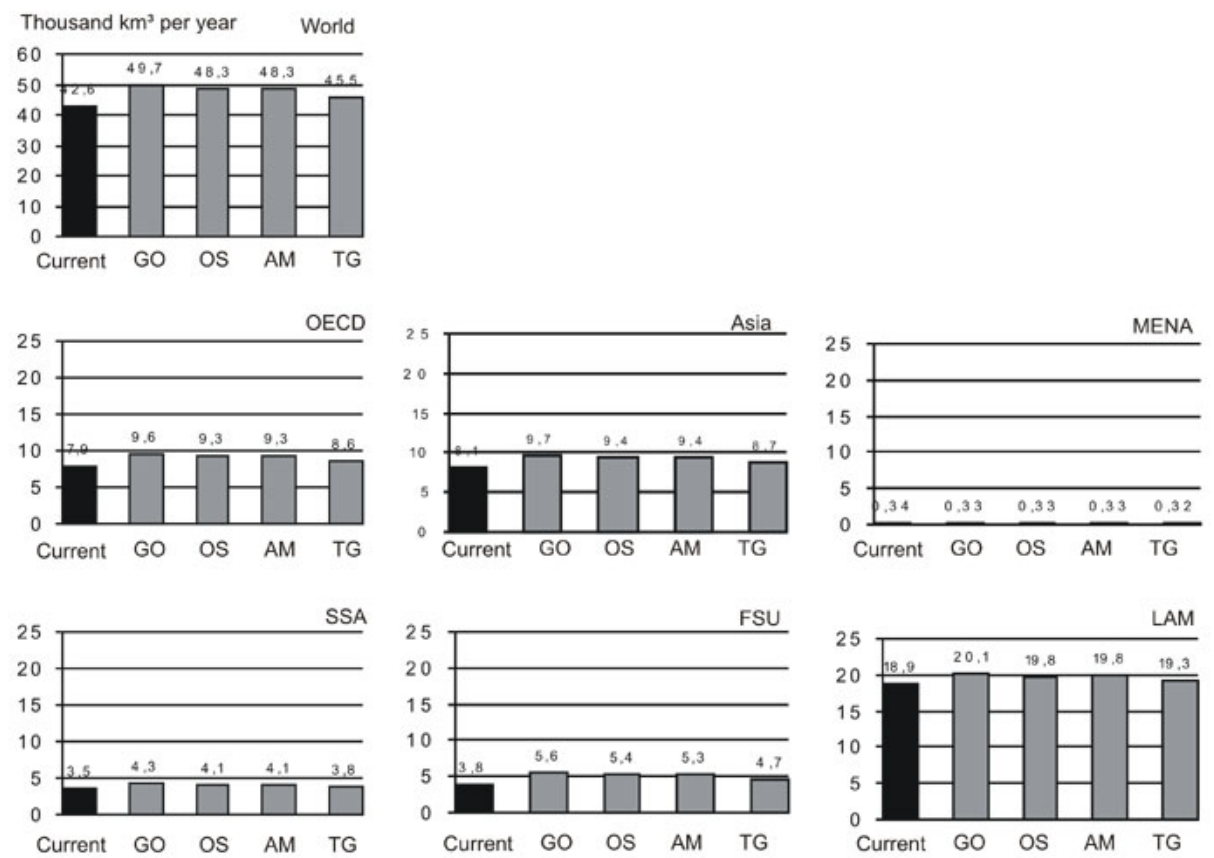

(b)
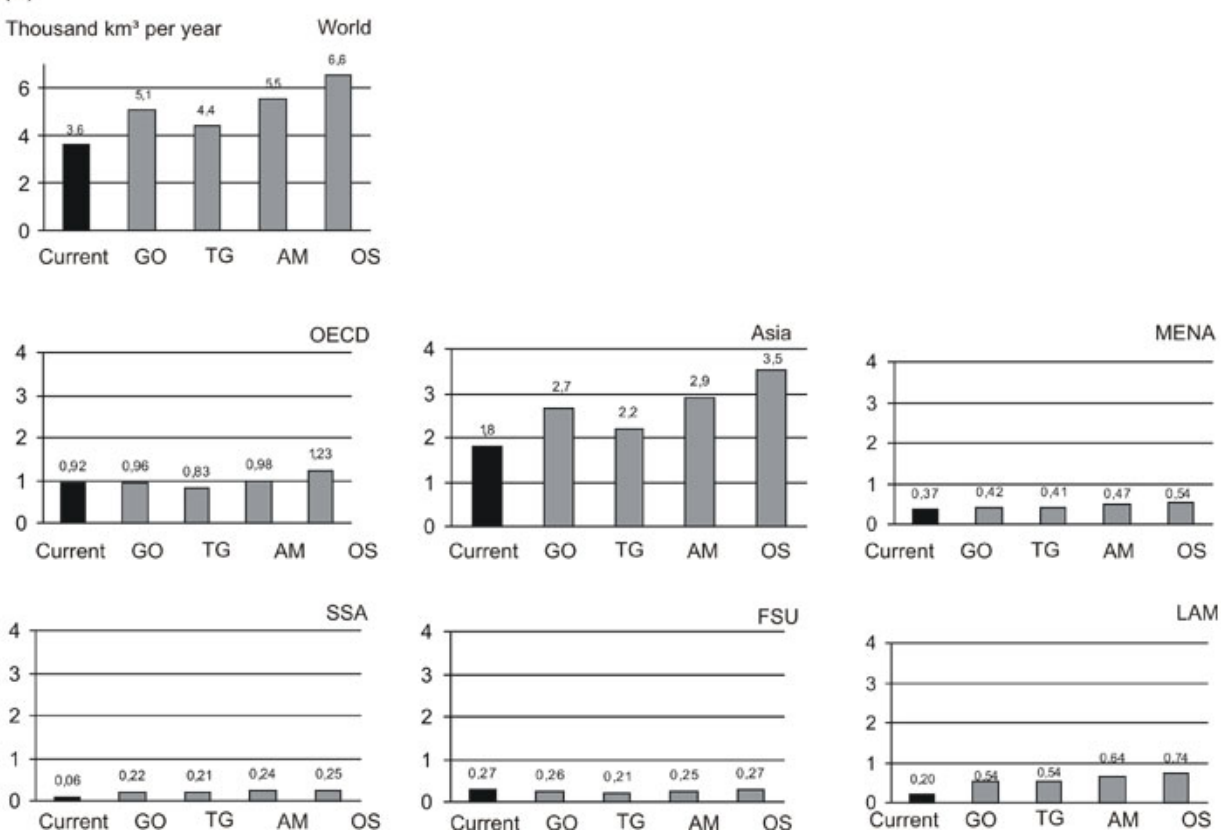
America (factor of 2.5 to 3 ) and Sub-Saharan Africa (factor of 3 in both scenarios).

We have seen that net water availability will increase in nearly all regions (with the important exception of the MENA) because of climate change, and that water withdrawals will very greatly increase in Sub-Saharan Africa and Latin America. From the perspective of ecosystem services, these results imply an increase in services delivered by freshwater systems. But we have not yet examined the capability of freshwater ecosystems to deliver these services. As an indirect indicator of this capability, we assess the changes in water stress resulting from the computed changes in water availability and withdrawals. The concept of water stress is used in many water assessments to obtain a first estimate of the extent of society's pressure on water resources. As in other assessments (Alcamo et al. 2000, 2003b, Cosgrove and Rijsberman 2000, Vörösmarty et al. 2000, Takahashi et al. 2001), it is assumed here that the higher the level of water stress, the greater the limitations to freshwater ecosystems, and the more likely that chronic or acute shortages of water supply will occur. $\S$

Simulations for Global Orchestration in 2050 (Fig. 8 ) show that much of northern and southern Africa, as well as central and southern Asia, are in the "severe water stress" category. Some areas, especially in OECD countries, fall out of the severe stress category because of stabilizing withdrawals and increasing water availability due to higher precipitation under climate change. Currently, about a total of $18 \%$ of the world's river basin area falls into this category, having a population of about 2.3 billion people. Although the net area under severe water stress does not change significantly up to 2050, the number of people living in these river basins increases up to 4.9 billion under Global Orchestration, and 5.3 to 5.5 billion (about $60 \%$ of the world's population in 2050) under Adapting Mosaic and Order from Strength (because of the growth of developing country populations). With regard to changes in time, most river basins in the developing world have increasing water stress because of sharp increases in water withdrawals.

A particularly important aspect of increasing water stress is the likely increase in water pollution loadings to surface and groundwater, and the resulting risk of water contamination and reduced habitat of aquatic ecosystems. As a surrogate of water pollution loading, we compute return flows, which are the difference between withdrawals and consumption, and therefore, provide a rough estimate of the magnitude of wastewater discharged into the receiving water in a river basin. For the range of scenarios considered here, total return flows increase worldwide between 1995 and 2050 from $42 \%$ to $200 \%$, depending on the scenario, with the largest increases in Latin America (factor of 2 to 3) and Sub-Saharan Africa (factor of 3.5 to 5.5). The river basin area where return flows will double between 1995 and 2050 ranges from approximately 48.2 to 76.2 million $\mathrm{km}^{2}$ (depending on the scenarios) and contains from 3.9 to 6.7 billion people in 2050 (Fig. 8).

\section{Major uncertainties}

Although increasing withdrawals indicate increased freshwater services, especially to households and industry, the reliability of these services is not assured. The expansion of areas under severe water stress, as well as the intensification of water stress throughout most of the developing world, indicate increasing competition for water resources, and in some river basins, more frequent disruption of water supply. The unprecedented increases in return flows, especially in Latin America and Sub-Saharan Africa, will lead to large-scale degradation of water quality and interference with the delivery of freshwater services unless these return flows are subjected to wastewater treatment.

\section{Future Fuels from Nature: Modern Biofuels}

\section{Scenarios of modern biofuel use}

Terrestrial ecosystems provide society with a range of fuels, from fuelwood and peat to modern biofuels derived from agricultural and forestry wastes, as well as energy crops such as maize, sugar cane, and elephant grass. Traditional forms of biofuel such as fuelwood still represent a major share of the global energy system, but the MA scenarios assume that they will be gradually replaced by other energy carriers. At the same time, the scenarios assume an expansion of modern biofuels as a substitute for fossil fuels in order to reduce greenhouse gas emissions, and because biofuel prices may become cheaper as the reserves of oil and other fossil fuels are depleted.

The AIM model, used here to estimate future biofuel production, makes a comprehensive estimate of the 
Fig. 8. (a) Areas under severe water stress in 2050 under Global Orchestration, (b) Areas where return flows increase at least $100 \%$ between now and 2050 under Global Orchestration. FSU = Former Soviet Union, SSA = Sub-Saharan Africa, LAM = Latin America, MENA = Middle East \& North Africa. Scenario names: $\mathrm{GO}=$ Global Orchestration; $\mathrm{TG}=$ TechnoGarden; AM=Adapting Mosaic; OS=Order from Strength. WaterGAP model calculations.

(a)

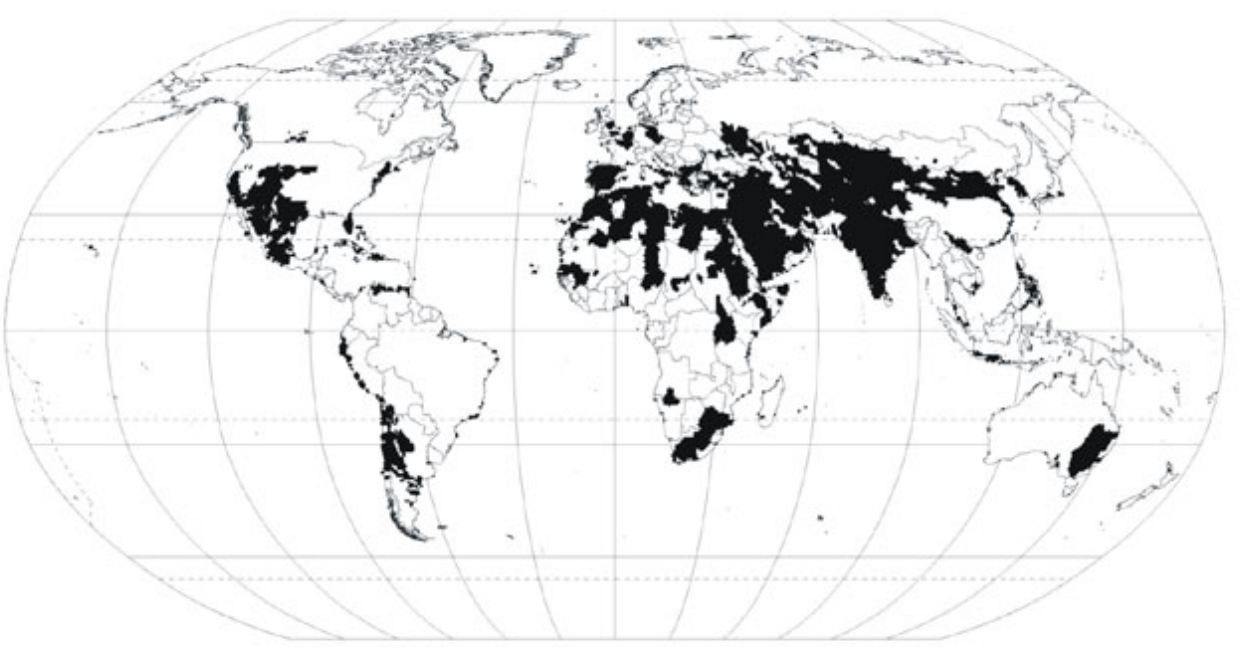

(b)

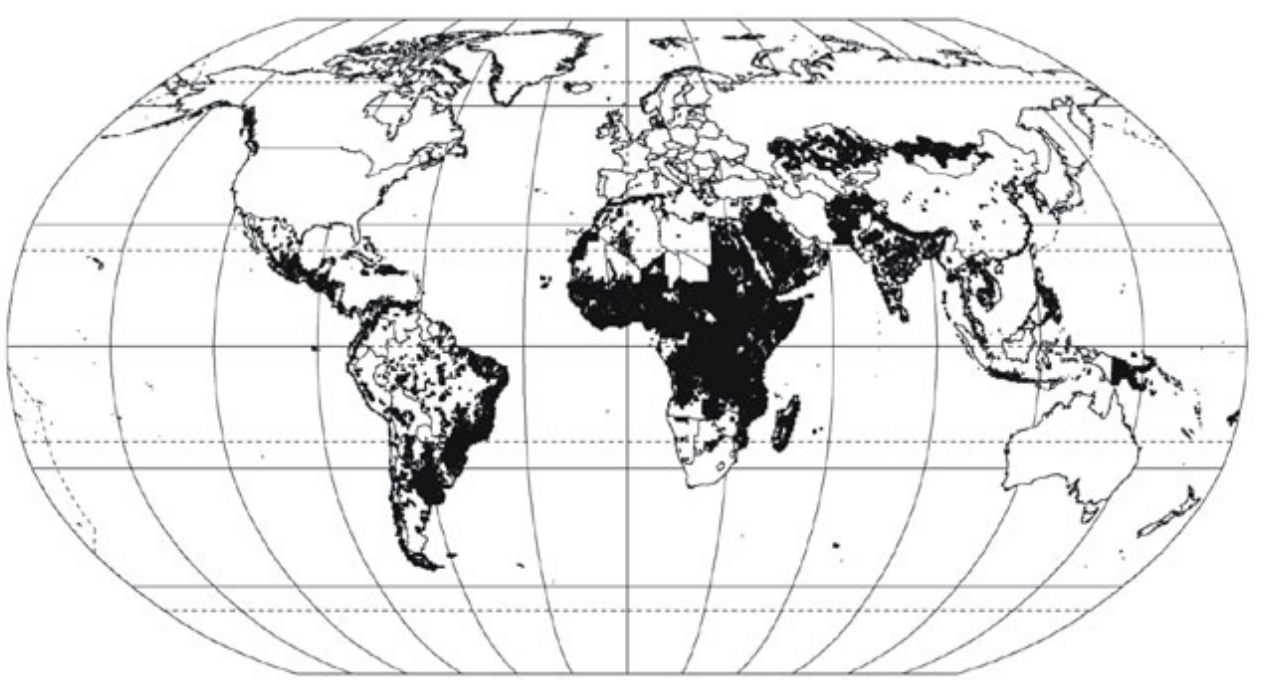


Fig. 9. Total modern biofuel production in 2050 [megatons per year]. FSU = Former Soviet Union, SSA $=$ Sub-Saharan Africa, LAM = Latin America, MENA = Middle East \& North Africa. Scenario names: $\mathrm{GO}=$ Global Orchestration; $\mathrm{TG}=$ TechnoGarden; $\mathrm{AM}=$ Adapting Mosaic; OS=Order from Strength. AIM model calculations.

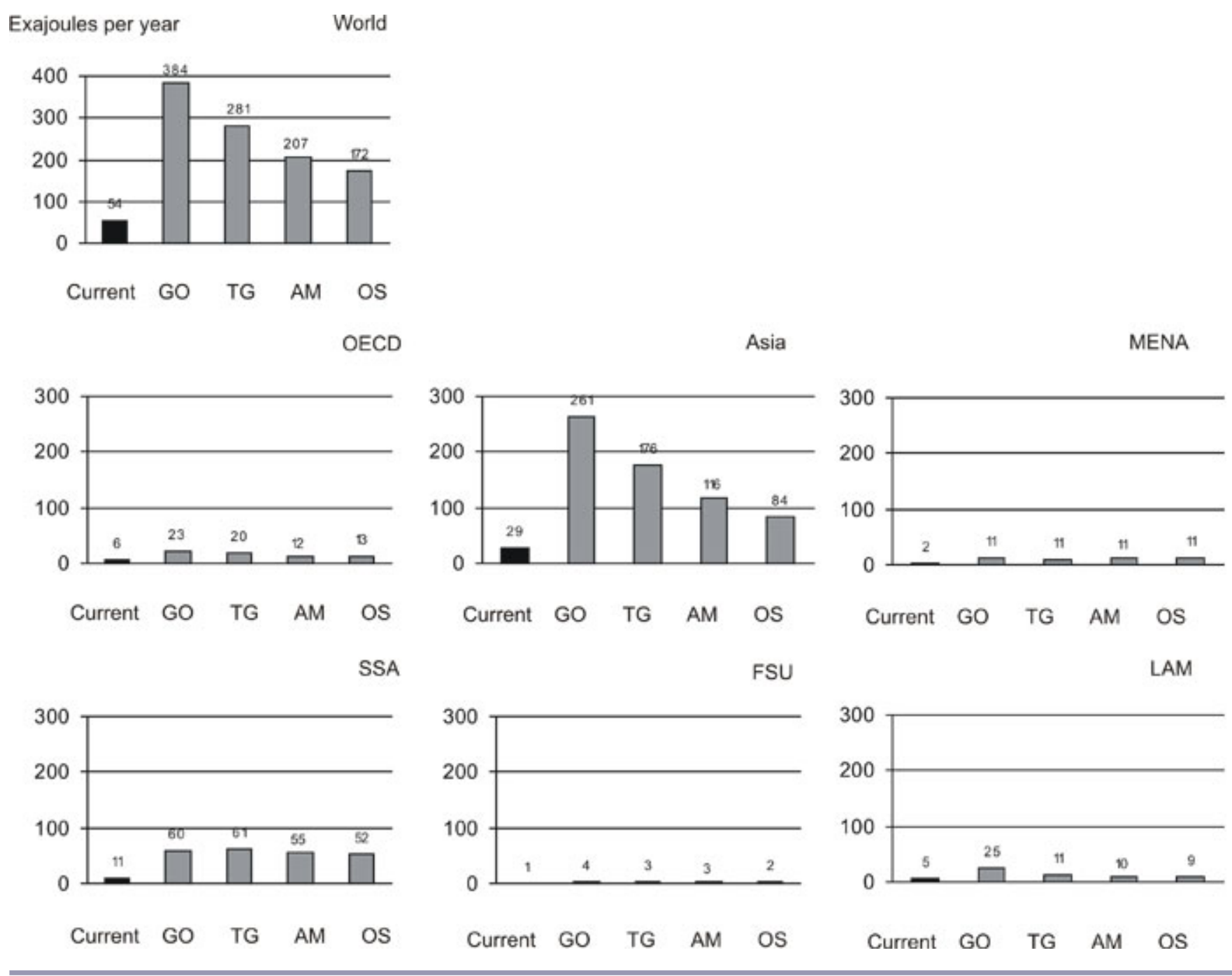

future consumption and mix of all modern fuels in different world regions (Kainuma et al. 2002). Preferences for biofuels and other energy carriers are determined by their future prices. An energy carrier is also assigned an environmental premium if it produces comparatively low emissions. Future investments in energy technology steadily increase the efficiency of energy use and biofuel production.

The scenarios show that Asia, the MENA, and SubSaharan Africa are expected to have the largest increases in modern biofuels production because of their access to relatively cheap and productive land for growing biofuel crops, which gives biofuels a future price advantage over other energy carriers (Fig. 9). All regions show a large increase in biofuel production under Global Orchestration (a factor of seven worldwide) because of the more rapid depletion and higher prices of fossil fuels under this scenario. The total energy demand is also higher in this scenario because of strong economic growth. The next largest production occurs under 
TechnoGarden (an increase of a factor 5 worldwide) because it is assumed here that fossil fuels are replaced by biofuels in order to reduce greenhouse gas emissions. Biofuel production is lower in the other scenarios because of their lower energy demands and greater requirements for food, which leads to stronger competition for land.

\section{Major uncertainties}

Although the preceding calculations show the high potential demand for future biofuels, it is also important to take into account factors that may limit the future supply of biofuels. One important factor, competitive land use, was included in the calculations, but other factors, such as the possible impact of biofuels on soil, water, and regional air quality, were not included.

\section{REGULATING ECOSYSTEM SERVICES}

Regulating ecosystem services, as defined by the MA (2003), are services provided by ecosystems in the form of regulation of environmental conditions. These include:

- climate regulation (through modulation of the carbon cycle and other aspects of the climate system by ecosystems);

- $\quad$ erosion control (through soil retention);

- $\quad$ air quality maintenance (through absorption of harmful substances by ecosystems);

- water regulation and water purification (through mitigating effects of ecosystems on extremes of runoff and accumulation of harmful substances);

- human disease control (through ecosystem control of the spread of human disease vectors);

- $\quad$ biological pest and disease control (through ecosystem control of the spread of crop pests and pathogens);

- pollination (through influences of ecosystems on the abundance and distribution of pollinators); and
- coastal protection (through the protecting effect of ecosystems, such as coral reefs and mangroves, on coastal structures).

Here, we focus on climate regulation and erosion control, which are especially amenable to quantitative analysis using existing models.

\section{Climate Regulation and Carbon Storage}

Scenarios of climate regulation and carbon storage

The biosphere plays an active role in regulating climate by influencing the mass, energy, and moisture fluxes between the biosphere, ocean, and atmosphere. Among its many influences, the biosphere respires and takes up $\mathrm{CO}_{2}$, absorbs solar radiation, and re-emits or reflects it back to the atmosphere. The biosphere also retains precipitation on plant surfaces, evaporates it back to the atmosphere, and transpires moisture from the soil to the atmosphere. According to current estimates, the global biosphere is actively slowing down climate change by absorbing more $\mathrm{CO}_{2}$ from the atmosphere than it releases, thereby retarding the accumulation of $\mathrm{CO}_{2}$ in the atmosphere (Schimel et al. 2001). Currently, the terrestrial biosphere each year takes up between 2 and $4 \mathrm{Gt}$ more carbon than it emits (Schimel et al. 2001). This is only a temporary and highly variable condition, however, caused by a net increase in forested area and increasing plant productivity stimulated by higher atmospheric $\mathrm{CO}_{2}$ levels and increasing temperatures. It is now believed that the biosphere may shift from being a net sink to being neutral or even a net source of $\mathrm{CO}_{2}$ over the time scale of decades, depending on long-term climatic cycles and shorter-term human interventions (Cramer et al. 2001). This change could enhance the radiative forcing related to greenhouse gases and hence accelerate climate change.

In our analysis, we have estimated one aspect of the biosphere's capability to regulate climate, namely its net primary productivity (NPP). This is a measure of the carbon taken up through plant photosynthesis in the biosphere (and taken up from the atmosphere) minus the $\mathrm{CO}_{2}$ released through respiration of flora and fauna. As noted below, the long-term NPP is an incomplete measure of the regulatory capacity of the biosphere, because soil respiration may also change in response to climate change and land use. 
In the IMAGE 2.2 model, NPP is simulated in time on the basis of changes in the various carbon pools of the biosphere, including impacts of climate and land-use change. The various MA scenarios show an increase in NPP from about $61.4 \mathrm{Gt} \mathrm{C} \mathrm{a}^{-1}$ in 2000 (within the typical range of other estimates; cf. Cramer et al. 1999) to 70.4 to $74.6 \mathrm{Gt} \mathrm{C} \mathrm{a}^{-1}$ in 2050 . The largest increase occurs under the Global Orchestration scenario because it has the fastest increases in atmospheric $\mathrm{CO}_{2}$ and temperature, which stimulate plant growth in the biosphere and further enhance its uptake of $\mathrm{CO}_{2}$ from the atmosphere. Conversely, the TechnoGarden scenario has the smallest carbon uptake because it has the slowest increases in $\mathrm{CO}_{2}$ and temperature.

\section{Major uncertainties}

Although NPP is increasing in all scenarios, it is an incomplete measure of the capability of the biosphere to regulate climate because it does not take into account the effects of natural disturbances on the biosphere (fire, windstorms, etc.) nor the potentially changing influence of soil organisms on atmospheric $\mathrm{CO}_{2}$. It also omits other factors that could affect the future capability of the biosphere to regulate climate, for example, the impact of future changes in vegetation on fluxes of energy and moisture between the biosphere and atmosphere. In addition, the response of the biosphere to changes in future $\mathrm{CO}_{2}$ and temperature are not well understood, and hence it may be incorrectly represented in current models (cf. Cramer et al. 2001). Apart from these uncertainties, the future uptake of $\mathrm{CO}_{2}$ in the biosphere may very well be determined by future forestry practices and "carbon plantations" explicitly grown to enhance the uptake of $\mathrm{CO}_{2}$ from the atmosphere.

\section{Erosion Control and Soil Degradation}

\section{Scenarios of changing risk of water-induced soil erosion}

Erosion of land surfaces often increases sediment loads of rivers and streams, and can interfere with navigation and water supply associated with these waters (United Nations Environment Programme (UNEP) 2002). Soil erosion is also an important cause of degradation of agricultural land. Estimates of losses in global crop productivity caused by erosion during different periods range from about $0.5 \%$ to $12.7 \%$ (Crosson 1994, Oldeman 1998, den
Biggelaar et al. 2004a, 2004b). Therefore, the overall capability of soil ecosystems to control erosion is viewed as a key regulating ecosystem service. Here, we evaluate future trends in erosion control by assessing changing risk of soil erosion.

Soil erosion takes different forms, including water erosion, wind erosion, physical compaction, salinization, and various forms of chemical degradation. In our analysis, we focus on water erosion because of its worldwide importance. Using the methodology of UNEP's Global Environmental Outlook (Hootsman et al. 2001, Potting and Bakkes 2004), we calculate an index of risk of water erosion based on the erodibility of terrain (a function of soil and terrain properties), rainfall erosivity (dependent on monthly precipitation), and land-cover pressure (which ranges from large for most types of agricultural land to small for most other land covers). In Fig. 10, we present results for the area deemed to have high risk of water erosion. The differences between scenarios are not as great as differences between regions. In Sub-Saharan Africa, the area under high risk of water erosion approximately doubles under all scenarios between 1995 and 2050 because of a net increase in precipitation, the widespread replacement of natural vegetation, and the expansion of agriculture onto terrain susceptible to water erosion. Substantial but less extreme increases in the area under risk occur in Latin America and Asia. The Order from Strength scenario has the highest risk of water erosion because more natural vegetation is replaced by agriculture in this scenario than in other scenarios, and because it experiences a large increase in precipitation.

\section{Major uncertainties}

The estimation of risk of water erosion does not take into account management practices that have an important effect on the rate of water erosion. On one hand, the risk of erosion is magnified by soil tillage and other mechanical disturbances. On the other hand, it can be minimized by conservation measures, such as contour plowing and terracing. 
Fig. 10. Global area of soils with a high risk of water erosion in 2050. FSU = Former Soviet Union, SSA = Sub-Saharan Africa, LAM = Latin America, MENA = Middle East \& North Africa. Scenario names: $\mathrm{GO}=$ Global Orchestration; $\mathrm{TG}=$ TechnoGarden; AM=Adapting Mosaic; OS=Order from Strength. Calculations using UNEP-GEO methodology (see text).

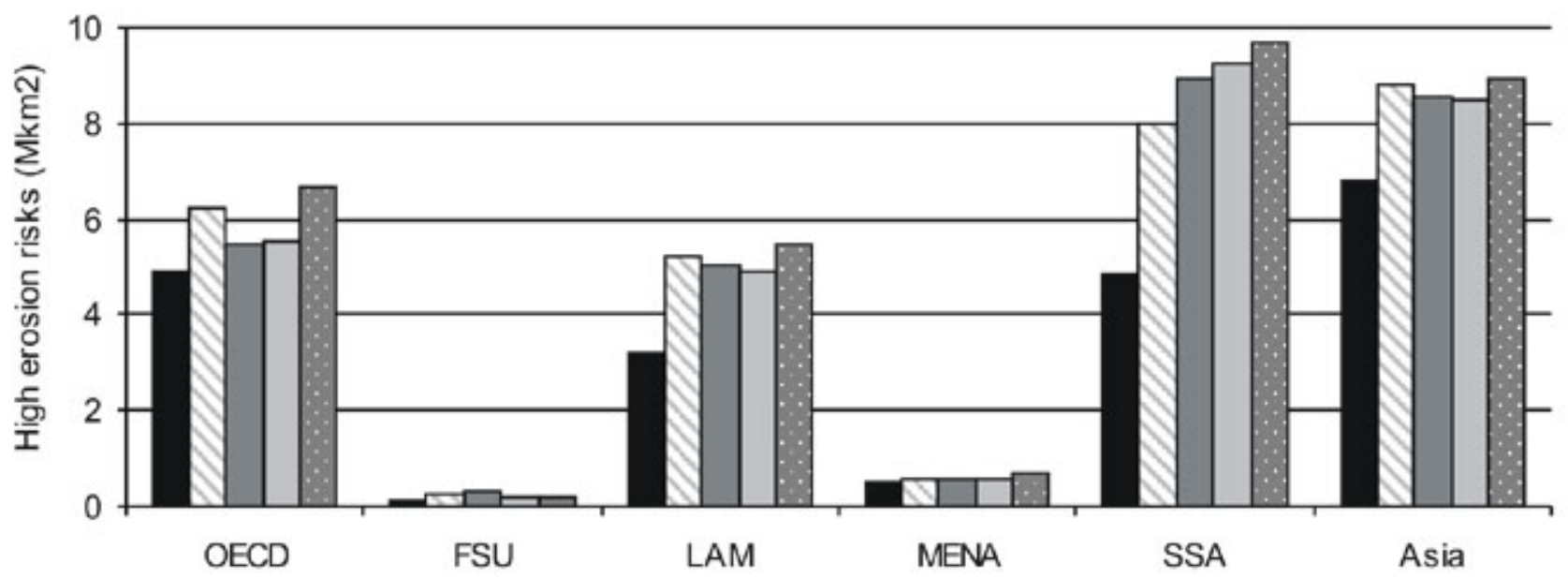

1995 口Adapting Mosaic $\square$ TechnoGarden $\square$ Global Orchestration $\square$ Order from Strength

\section{MAIN FINDINGS ACROSS THE SCENARIOS}

\section{The Magnitude of Ecosystem Services Increase, but Their Reliability is Unclear}

The results for future ecosystem services can be interpreted as the demand and supply sides of a balance sheet. The demand side presents a mostly optimistic view of the future, with the demand for services, such as food, water, and fuels, expanding across all scenarios and for almost all categories and regions. The largest increases occur under the Global Orchestration and TechnoGarden scenarios, where income steadily grows, augmenting the purchasing power of individuals, and society invests heavily in technology and reduces trade barriers so that resources and services are cost-effectively extracted from nature. Up to 2050, global cereal consumption increases by a factor of 1.5 to 1.7 (depending on the scenario), fish consumption (up to the 2020s) by a factor of 1.3 to 1.4 , water withdrawals for households, industry, and other uses by a factor of 1.2 to 1.8 , and biofuel production by a factor of 5.1 to 11.3 . But some consumption gaps remain between regions and countries, and food security in Sub-Saharan Africa remains particularly low.

The view from the supply side of the balance sheet is less optimistic because the increase in ecosystem services incurs new costs, and the capability of ecosystems to supply these services is uncertain:

- Although the demand for food and biofuels grows, there are signals of continuing or impending difficulty in producing the needed crops: soil erosion sharply increases in SubSaharan Africa under most scenarios, and agricultural production in the MENA may be at higher risk because climate change decreases the water available for crop 
irrigation (perhaps requiring more food imports).

- The global demand for fish grows, but it is questionable whether marine fisheries can keep up with this demand (even taking into account an increase in aquaculture-produced fish). For instance, our simulations indicate that ecological limits will make an increase in production unlikely in two out of the three important marine fisheries that were examined.

- Although increasing income will make it possible to deliver freshwater services to many more households and industries in the future, a consequence of increasing water withdrawals will be a significant intensification of water stress throughout most of the developing world.

Although our simulations raise doubt about the reliability of future ecosystem services, they do not indicate the likelihood that thresholds or breaking points in nature will be reached. Such thresholds are difficult to identify globally, and data deficiencies make it difficult to include the non-linear dynamics needed to simulate breaking points with the current generation of global models. Yet the new generation of global models should deal with these issues because large-scale ecological thresholds and breaking points have already been documented. For example, large fisheries have abruptly collapsed in many coastal areas (Jackson et al. 2001); El Nino events have been related to serious cholera outbreaks in the Horn of Africa (Anonymous 1998) and Bangladesh (Pascual et al. 2000); and the introduction of the zebra mussel into aquatic systems has caused substantial economic damage in the United States (Ram et al. 1992). Other plausible future breaking points have been hypothesized as part of the storylines of the MA scenarios (Cork et al. 2005).

\section{Tradeoffs between Services Will Intensify}

Not only do the scenarios raise some doubt about the feasibility of the expansion of services, but they also imply that one service may be gained at the expense of another. In developing countries, increased production of food and biofuels will be achieved at least partly by expanding agricultural land, and at the expense of uncultivated natural land.
Our simulations show that, as a rough first estimate, between $10 \%$ and $20 \%$ of current grassland and forest land could be lost between 2000 and 2050, mainly due to the expansion of agriculture (and secondarily, because of the expansion of cities and infrastructure) (Fig. 5). The ecosystem services associated with this land (genetic resources, wood production, habitat for terrestrial biota and fauna) will be lost. Where agricultural practices are intensified, the side effects of this intensification (contamination of groundwater, transport of nitrogen to coastal zones) could limit the ecosystem services provided by groundwater, surface waters, and the coastal zone (fishery, recreation).

Another important tradeoff is expected for freshwater services. The scenarios project a much higher delivery of freshwater services to households and industry, especially in developing countries. In particular, the development of water infrastructure and delivery of clean water to households in developing countries can significantly reduce water-related diseases. But a spinoff of increased withdrawals will be large increases in return flows (wastewater), especially in Latin America (factor of 2 to 4 ) and Sub-Saharan Africa (factor of 3.6 to 5.6) between 1995 and 2050 . Where return flows are discharged untreated into surface waters and groundwater, they will pose a risk of contamination for society and reduce the habitat suitable for freshwater fish and other organisms. It would be ironic if improved delivery of freshwater services to households would cause a deterioration of other freshwater services. Ecosystem tradeoffs are further elaborated by Rodríguez et al. (2005).

\section{More Rapid Changes Will Occur in Some Hot- spot Regions}

The simulations suggest that three parts of the world in particular may undergo faster changes in ecosystem services than other regions. These regions merit special monitoring and attention from the scientific community:

- Central Africa-The demand for food and water could rapidly expand in the central part of Africa as part of the economic development of this region. A fraction of increased food demand is likely to be provided by expanding agricultural land onto forest and grassland at the likely expense of 
services provided by these biomes (disease regulation, fuelwood, medicinal products). Another part of increasing food demand will come from intensification of farming (including higher inputs of nitrogen fertilizer and pesticides), and this poses increased risk of contamination of surface and groundwaters. Meeting the rapid growth in water demand will require unprecedented investments in new water infrastructure, and under some scenarios, this will cause a rapid increase in untreated return flows to freshwater systems.

- Middle East-The simulations indicate that rapid population growth and rising incomes in MENA countries could lead to a still higher level of dependency on food imports. The pressure on remaining ecosystems as result of land scarcity is likely to increase. Water availability may decrease as a result of climate change. Rising incomes will also put further pressures on limited water resources and this could either stimulate innovative approaches to water conservation or limit economic development.

- South Asia-The simulations point toward continuing deforestation in this region, as well as increasingly intensive industrial-type agriculture, rapidly increasing water withdrawals and return flows and further intensive water stress. This is one of the regions most likely to reach breaking points in its ecosystems.

\section{NEXT STEPS}

The simulations have shown a positive balance of increasing demand and supply of ecosystem services, especially in developing countries. However, this comes at the cost of increased risks and tradeoffs of services. The challenge then is how to cope with these risks and avoid the curtailment of ecosystem services. For a comprehensive review of response strategies, the reader is referred to the MA's analysis of 74 response options (Chopra and Leemans 2005). Here, we make three specific recommendations:

\section{Strengthen Global Early Warning Systems}

Faced with high risks to ecosystem services, a wise strategy would be to strengthen efforts to develop global early warning systems for detecting thresholds and breaking points in nature's provision of services. (The MA's Conditions and Trends Report (2005) also identifies the need to better understand "the structural and dynamic characteristics of systems that lead to threshold and irreversible changes.") We believe that scientific understanding can be combined with earth observation technology to give an early indication of risks to food production, water availability, and other vital ecosystem services, and to enable a timely response to these risks.

\section{Add a Foresight Component to the Implementation of Ecosystem-related International Treaties}

Current treaties having to do with the world's ecosystems (Convention on Biodiversity, Convention to Combat Desertification, Convention on the Law of the Sea, Ramsar Wetlands Convention) are primarily concerned with the protection of current global resources instead of planning for the future of these resources. We recommend, however, that Parties to these Conventions also take into account future developments in ecosystems when they develop policies to implement the conventions. This broadened perspective would help decision makers and stakeholders develop better policies to avoid future collapses in the services provided by biodiversity, wetlands, and drylands. This futures perspective can be brought into the activities around the Conventions by conducting scenario analyses of the type described in this paper or by using other foresight methodologies.

\section{Develop New Modeling Strategies}

We have found that the simulations of global ecosystems in the MA scenario study are unable to depict low-probability yet plausible breaking points in world ecosystems. This deficiency of current global models is understandable because of their coarse resolution and weak representation of nonlinear linkages in the earth system. Yet models are needed to anticipate ecosystem collapses so that policies can be developed to avoid or adapt to these collapses. The MA's Conditions and Trends Report 
(2005) also points out the need for "both conceptual and quantitative models that can begin to give both scientific and policy communities advance warning of when the capacity of systems is beginning to be eroded, or thresholds likely to be reached." Hence, we recommend that the modeling community give special attention to developing new strategies for simulating world ecosystems. Possible actions are: (i) developing and using more detailed local or regional models of ecosystem services that are representative of larger regions, (ii) increasing the resolution and non-linear couplings in global models by taking advantage of new global data sets (e.g., from earth observation platforms) and new computational approaches (e.g., parallel programming), and (iii) developing nested models that combine the capabilities of regional and global models.

These and other advances in our understanding of worldwide ecosystem services may enable us to gain a favorable balance sheet of nature's services in the coming decades.

Responses to this article can be read online at:

http://www.ecologyandsociety.org/vollo/iss2/art19/responses/

\section{Acknowledgments:}

The authors are indebted to the following colleagues for their contributions to the analyses presented in this paper: Elena Bennett, Lex Bouwman, Stephen Carpenter, Bas Eickhout, Martina Floerke, Jonathan Foley, Rattan Lal, Michael Maerker, Tsuneyuki Morita, Brian O'Neill, Prabhu Pengali, Garry Peterson, Mark Rosegrant, Kiyoshi Takahashi, and Monika Zurek. The authors acknowledge the useful comments about the analyses presented in this paper by Christopher Field, Bach Tan Sinh, and Allen Hammond. Support for the work in this paper was provided by the following organizations: the Federal Ministry of the Environment, Natural Resources and Nuclear Safety, Germany to Wolfgang Cramer; the Netherlands Environmental Assessment Agency to Detlef van Vuuren; and the National Institute of Environmental Studies, Japan to Toshihiko Masui.

\section{LITERATURE CITED}

Alcamo, J., D. van Vuuren, C. Ringler, J. Alder, E. Bennett, D. Lodge, T. Masui, T. Morita, M. Rosegrant, O. Sala, K. Schulze, and M. Zurek. 2005a. Methodology for developing the MA scenarios. Chapter 6 in S. Carpenter, P. Pingali, E. Bennett, and M. Zurek, editors. Scenarios of the Millennium Ecosystem Assessment. Island Press, Oxford, UK.

Alcamo, J., D. van Vuuren, W. Cramer, J. Alder, E. Bennett, S. Carpenter., J. Foley, M. Maerker, T. Masui, T. Morita, B. O'Neill, G. Peterson, C. Ringler, M. Rosegrant, and K. Schulze. 2005b. Changes in ecosystem goods and services and their drivers across the scenarios. Chapter 9 in $\mathrm{S}$. Carpenter, P. Pingali, E. Bennett, and M. Zurek, editors. Scenarios of the Millennium Ecosystem Assessment. Island Press, Oxford, UK.

Alcamo, J., P. Döll, T. Henrichs, F. Kaspar, B. Lehner, T. Rösch, and S. Siebert. 2003a. Development and testing of the WaterGAP 2 global model of water use and availability. Hydrological Sciences 48(3):317-337.

Alcamo, J., P. Döll, T. Henrichs, F. Kaspar, B. Lehner, T. Rösch, and S. Siebert. 2003b. Global estimation of water withdrawals and availability under current and "business as usual" conditions. Hydrological Sciences 48(3):339-348.

Alcamo, J., T. Henrichs, and T. Rösch, 2000. World water in 2025: global modeling scenarios for the World Commission on Water for the twenty-first century. World Water Series Report 2, Center for Environmental Systems Research, University of Kassel, Germany.

Alcamo, J., R. Leemans, and E. Kreileman, editors. 1998: Global change scenarios of the 21st century. Results from the IMAGE 2.1 model. Pergamon \& Elseviers Science, London, UK.

Anonymous. 1998. Cholera epidemics in the Horn of Africa. Weekly Epidemiological Record 3:73 (27):201-208.

Carpenter, S., P. Pingali, E. Bennett, and M. Zurek, editors. 2005. Scenarios of the Millennium Ecosystem Assessment. Island Press, Oxford, UK.

Chopra, K., and R. Leemans, editors. 2005. The 
responses assessment of the Millennium Ecosystem Assessment. Island Press, Oxford, UK.

Cork, S., G. Peterson, G. Petschel-Held, J. Alcamo, J. Alder, E. Bennett, E. Carr, D. Deane, G. Nelson, and T. Ribeiro. 2005. Four Scenarios. Chapter 8 in S. Carpenter, P. Pingali, E. Bennett, and M. Zurek, editors. Millennium Ecosystem Assessment: Volume 2. Scenarios Assessment. Island Press, Oxford, UK.

Cosgrove, W., and F. Rijsberman. 2000. World water vision: making water everybody's business. World Water Council, Earthscan Publications, London, UK.

Cox, P. M., R . A. Betts, C. D. Jones, S. A. Spall, and I. J. Totterdell. 2000. Acceleration of global warming due to carbon-cycle feedbacks in a coupled climate model. Nature 408: 184-187.

Cramer, W., A. Bondeau, F. I. Woodward, I. C. Prentice, R. A. Betts, V. Brovkin, P. M. Cox, V. Fisher, J. Foley, A. D. Friend, C. Kucharik, M. R. Lomas, N. Ramankutty, S. Sitch, B. Smith, A. White, and C. Young-Molling. 2001. Global response of terrestrial ecosystem structure and function to $\mathrm{CO}_{2}$ and climate change: results from six dynamic global vegetation models. Global Change Biology 7(4):357-373.

Cramer, W., D. W. Kicklighter, A. Bondeau, B. Moore, III, G. Churkina, B. Nemry, A. Ruimy, A. L. Schloss, and Participants of "Potsdam'95." 1999. Comparing global models of terrestrial net primary productivity (NPP): overview and key results. Global Change Biology 5(1):1-15.

Crosson, P. 1994. Degradation of resources as a threat to sustainable agriculture. Paper presented at the First World Congress of Professionals in Agronomy. 5-8 September 1994, Santiago, Chile. (Cited in World Resources Institute. 1998. World resources 1998-1999. Oxford University Press, New York, New York, USA. p. 157.)

den Biggelaar, C., R. Lal, K. Wiebe, and V. Breneman. 2004a. The global impact of soil erosion on productivity. I. Absolute and relative erosioninduced yield losses. Advances in Agronomy 81:148.

den Biggelaar, C., R. Lal, K. Wiebe, H. Eswaran, V. Breneman, and P. Reich. 2004b. The global impact of soil erosion on productivity. II. Effects on crop yields and production over time. Advances in Agronomy 81:49-95.

Green, P., C. J. Vörösmarty, M. Meybeck, J. Galloway, and B. J. Peterson. 2004. Pre-industrial and contemporary fluxes of nitrogen through rivers: a global assessment based on typology. Biogeochemistry 68:71-105.

Heymans, J. J., L. T. Shannon, and A. Jarre. 2004. Changes in the Northern Benguela ecosystem over three decades: 1970s, 1980s and 1990s. Ecological Modelling 172:175-195.

Hootsman, R. M., A. F. Bouwman, R. Leemans, and G. J. Kreileman. 2001. Modelling land degradation in IMAGE 2. RIVM report 481508009. National Institute for Public Health and the Environment, Bilthoven, the Netherlands.

IMAGE-Team. 2001. The IMAGE 2.2 implementation of the SRES scenarios. A comprehensive analysis of emissions, climate change and impacts in the 21st century. [CD-ROM.] RIVM CD-ROM publication 481508018. National Institute for Public Health and the Environment, Bilthoven, the Netherlands.

Intergovernmental Panel on Climate Change (IPPC). 2001. Impacts, adaptation, and vulnerability. IPCC, Cambridge University Press, Cambridge, UK.

Jackson, J. B. C., M. X. Kirby, W. H. Berger, K. A. Bjorndal, L. W. Botsford, B. J. Bourque, R. H. Bradbury, R. Cooke, J. Erlandson, J. A. Estes, T. P. Hughes, S. Kidwell, C. B. Lange, H. S. Lenihan, J. M. Pandolfi, C. H. Peterson, R. S. Steneck, M. J. Tegner, and R. R. Warner. 2001. Historical overfishing and the recent collapse of coastal ecosystems. Science 293:629-638.

Kainuma, M., Y. Matsuoka, and T. Morita. 2002. Climate policy assessment. Springer, Tokyo, Japan.

Lehner, B., P. Döll, J. Alcamo, T. Henrichs, and F. Kaspar. 2005. Estimating the impact of global change on flood and drought risks in Europe: a continental, integrated analysis. Climatic Change: in press.

Millennium Ecosystem Assessment (MA). 2003. Ecosystems and human well-being. A framework for assessment. Island Press, Washington, D.C., USA. 
Millennium Ecosystem Assessment (MA). 2005. Ecosystems and human well-being. Current state and trends. Island Press, Washington, D.C., USA.

Nelson, G., A. Janetos, E. Bennett, and A. Berhe. 2005. Drivers of change in ecosystem condition and services. Chapter 7 in S. Carpenter, P. Pingali, E. Bennett, and M. Zurek, editors. Scenarios of the Millennium Ecosystem Assessment. Island Press, Oxford, UK.

Oldeman, L. R. 1998. Soil degradation: a threat to food security. ISRIC Report 98/01. Wageningen, the Netherlands.

Pascual, M., X. Rodo, S. Ellner, R. Colwell, and M. Bouma. 2000. Cholera dynamics and El NinoSouthern Oscillation. Science 289:1766-1769.

Pauly, D., J. Alder, E. Bennett, V. Christensen, P. Tydemers, and R. Watson. 2003. The future for fisheries. Science 302(5649):1359-1361.

Potting, J., and J. Bakkes. 2004. The GEO-3 Scenarios 2002-2032. UNEP/RIVM. United Nations Environment Programme, Nairobi, Kenya.

Ram, J. L., P. Fong, R. P. Croll, S. J. Nichols, and D. Wall. 1992. The zebra mussel (Dreissena polymorpha), a new pest in North America: reproductive mechanisms as possible targets of control strategies. Journal of Invertebrate Reproductive Development 22:77-86.

Rodríguez, J. P., T. Beard, J. Agard, E. Bennett, S. Cork, G. Cumming, D. Deane. A. Dobson, D. Lodge, M. Mutale, G. Nelson, G. Peterson, and T. Ribeiro. 2005. Interactions among ecosystem services. Chapter 12 in S. Carpenter, P. Pingali, E. Bennett, and M. Zurek, editors. Scenarios of the Millennium Ecosystem Assessment. Island Press, Oxford, UK.

Rosegrant, M. W., M. S. Paisner, S. Meijer, and J. Witcover. 2001. Global food projections to 2020: emerging trends and alternative futures. 2020 Vision Food Policy Report. International Food Policy Research Institute, Washington, D.C., USA.

Sala, O., D. van Vuuren, H. Pereira, D. Lodge, J. Alder, G. Cumming., A. Dobson, V. Wolters, and M. Xenopoulos. 2005. Biodiversity across scenarios. Chapter 10 in S. Carpenter, P. Pingali, E. Bennett, and M. Zurek, editors. Scenarios of the Millennium Ecosystem Assessment. Island Press, Oxford, UK.

Schimel D. S., J. House, K. A. Hibbard, P. Bousquet, P. Ciais, P. Peylin, B. H. Braswell, M. J. Apps, D. Baker, A. Bondeau, J. Canadell, G. Churkina, W. Cramer, A. S. Denning, C. B. Field, P. Friedlingstein, C. Goodale, M. Heimann, R. A. Houghton, J. M. Melillo, B. Moore, III, D. Murdiyarso, I. Noble, S. W. Pacala, I. C. Prentice, M. R. Raupach, P. J. Rayner, R. J. Scholes, W. L. Steffen, and C. Wirth. 2001. Recent patterns and mechanisms of carbon exchange by terrestrial ecosystems. Nature 414:169-172.

Takahashi, K., Y. Matsuoka, Y. Shimada, and H. Harasawa. 2001. Assessment of water resource problems under climate change-considering interannual variability of climate derived from GCM calculations. Journal of Global Environmental Engineering 7:17-30.

United Nations Environment Programme (UNEP). 2002. Global Environment Outlook-3. United Nations, Geneva, Switzerland.

van Drecht, G., A. F. Bouwman, J. M. Knoop, A. H. W. Beusen, and C. R. Meinardi. 2003. Global modeling of the fate of nitrogen from point and nonpoint sources in soils, groundwater and surface water. Global Biogeochemical Cycles 17(4):26-126-20.

Vörösmarty, C. J., P. Green, J. Salisbury, and R. B. Lammers. 2000. Global water resources: vulnerability from climate change and population growth. Science 289:284-288.

Xenopoulous, M., D. Lodge, J. Alcamo, M. Märker, K. Schulze, and D. van Vuuren. 2005. Scenarios of freshwater fish extinctions from climate change and water withdrawals. Global Change Biology 11:1-8.

Great efforts were made to maximize the consistency of the MA global modeling exercise. A common spatial grid was used for spatially resolved calculations, and a consistent scheme was used to aggregate countries into specific regions for reporting purposes. A common time horizon and 
time intervals were used for reporting modeling results. Consistent inputs were also used to run the models as described below. Nevertheless certain internal inconsistencies between the models could not be avoided because of differences in modeling approaches and base data. The most noteworthy inconsistencies include the following, (1) different water balance schemes were used to compute potential vegetation within the IMAGE 2 model and river discharge within the WaterGAP model, (2) different procedures were used by the IMPACT and IMAGE 2 models to estimate potential crop yield, and (3) different land-use data were used by the AIM and IMAGE 2 models for computing emissions of greenhouse and other gases, and for other computations. Obviously, the quality of global scenario analyses would be improved by reducing these inconsistencies, and various international efforts such as the EU-sponsored Ensembles Project are making progress in this direction.

FThe three fisheries modeled are the Gulf of Thailand, the Central North Pacific, and North Benguela. The Gulf of Thailand is a shallow, tropical, coastal shelf system that has been heavily exploited since the 1960s. In the Central North Pacific, tuna fishing is one of the major economic activities. Recent assessments of the tuna fisheries indicate that top predators, such blue marlin and swordfish, have declined since the 1950s but their prey, small tunas, have increased (Cox et al. 2000). The North Benguela Current is an upwelling system off the west coast of Southern Africa. This upwelling system is highly productive, resulting in a rich living marine resource system that supports small, medium, and large pelagic fisheries (Heymans et al. 2004).

${ }^{\S}$ We use a common indicator of water stress, that is, the withdrawals-to-availability ratio (wta). This indicator implies that future water stress will tend to decrease in general because of growing water availability, but increase because of increased withdrawals. An often-used approximate threshold of severe water stress is a wta of 0.4 (Alcamo et al. 2000, 2003b, Cosgrove and Rijsberman 2000, Vörösmarty et al. 2000). River basins exceeding this threshold, especially in developing countries, are presumed to have a higher risk of chronic water shortages and risk to freshwater ecosystems. 